\title{
Research Article \\ Effect of HPPMS Pulse-Frequency on Plasma Discharge and Deposited AlTiN Coating Properties
}

\author{
Stefanie Severin, ${ }^{1}$ Muhammad Naveed, ${ }^{2}$ and Sabine Weiß ${ }^{1}$ \\ ${ }^{1}$ Department of Physical Metallurgy and Materials Technology, Brandenburg University of Technology (BTU) Cottbus-Senftenberg, \\ Konrad-Wachsmann-Allee 17, 03046 Cottbus, Germany \\ ${ }^{2}$ Bühler Leybold Optics GmbH, Siemens Straße 88, 63755 Alzenau, Germany
}

Correspondence should be addressed to Stefanie Severin; severste@b-tu.de

Received 23 June 2017; Revised 20 September 2017; Accepted 3 October 2017; Published 14 November 2017

Academic Editor: David Holec

Copyright (c) 2017 Stefanie Severin et al. This is an open access article distributed under the Creative Commons Attribution License, which permits unrestricted use, distribution, and reproduction in any medium, provided the original work is properly cited.

Coatings like TiAlN (titanium content more than 50\%) or AlTiN (aluminium content more than 50\%) are well established as hard and wear-resistant tool coatings, often prepared by physical vapour deposition (PVD) like arc evaporation or direct current magnetron sputtering (dcMS). With increasing challenges of operating conditions, there is a constant need for improvement of mechanical properties to withstand extreme loading conditions. This can be obtained by a higher amount of ionized sputtered metal atoms during the deposition process. To increase the metal ion flux a high-power pulse magnetron sputtering (HPPMS) was developed. In order to understand the relation between HPPMS process parameters and mechanical properties of the AlTiN coatings, the present study discusses how different pulse-frequencies (for a constant pulse length) influence AlTiN coating structure growth and their mechanical properties. In addition, film deposition rate and phase formation are influenced by altering process parameters like pulse length and frequency. Hence, different pulse-frequencies produce specific coatings with corresponding properties for functional requirements. Based on the established findings, answers to new scientific queries along with the demand to further optimize these coatings for tool applications are required.

\section{Introduction}

Transition-metal nitrides are often used as wear-resistant or super hard coatings for enhancing the lifetime of cutting and forming tools [1-4]. A well-known hard coating is $\mathrm{Al}_{x} \mathrm{Ti}_{x-1} \mathrm{~N}(x=0.6)$, deposited by dc-magnetron/arc sputtering, which offers an increase in component life due to high hardness and resistance against wear, corrosion, and oxidation at high temperatures [5-11]. With increasing challenges of operating conditions, a constant need in improvement of material properties is required to withstand extreme loadings. These properties can be achieved with smoother and denser coating structures resulting in better mechanical properties. A possibility of improving the film quality is to increase the number and the energy of ionized sputtered atoms, which is not possible with conventional dc coating processes. Hence, High Pulse Power Magnetron Sputtering (HPPMS) technology is introduced during the recent decade allowing higher ion densities and energies in comparison to conventional coating methods. The HPPMS is a further development of dc-magnetron sputtering, where a pulsed direct current power supply is used to ignite the plasma discharge in specific intervals. The main differences between dcMS and HPPMS are the discharge behaviour and the plasma composition during the coating process. In conventional dcMS, an increase in plasma and power density is limited due to the thermal load on the target [12]. In contrast, the pulsed power supply enables high-density plasma in front of the sputtering source with peak discharge currents in the order of a few $\mathrm{A} / \mathrm{cm}^{2}$ and a peak power density of several $\mathrm{kW} / \mathrm{cm}^{2}$. The pulsed DC voltage with very low duty cycles $<10 \%$ provides additional process parameters for tailoring coating growth and coating properties and to optimize the performance of compound films [13]. The resulting high-power density at the target leads to high electron densities in the magnetron confinement ("magnetic trap") increasing the probability of ionization between sputtered 
metal atoms and energetic electrons [14]. This enables a high degree of ionization of the sputtered material, in comparison to conventional dcMS where the amount of ionized atoms is generally very low [15]. The high amount of ionized sputtered atoms opens new opportunities in controlling the film growth by influencing the layer-forming metal ion movement within magnetic and/or electric fields [16]. These facts result in growth of denser and smoother coatings along with uniform coating deposition and film thickness on planar and complex-shaped geometries [13]. The ion-to-neutral flux ratio, the energy of the bombarding ions, their nature, and angle of incidence during the film growth affect the plasmafilm interface during film growth as well. These parameters determine the efficiency of the momentum transfer to the adatoms depending on ionization rate at the target and the probability to reach the substrate. Moreover, the velocity of the impinging ions originates from their kinetic energy after traversing the plasma and from their acceleration within the substrate bias potential in a voltage sheath in front of a biased substrate [13].

Due to the above-mentioned reasons, HPPMS is considered beneficial as it offers new options in coating growth and composites coatings. Especially on complex formed substrates or tools HPPMS enables a constant film thickness. For further development of AlTiN hard coatings and their derivatives through HPPMS, it is necessary to analyse and understand the correlation between selected HPPMS process parameters, related plasma conditions, and the mechanical properties of the respective coatings. In the present study a correlation between deposition conditions at various frequencies (constant pulse duration) and structure, deposition rates, phase formation, and mechanical properties is discussed for AlTiN coatings. Therefore, the measured current-voltage $(I-V)$ curves are used to explain how the selected pulse-frequencies from $100 \mathrm{~Hz}$ to $500 \mathrm{~Hz}$ influence the plasma discharge and, consequently, the AlTiN film properties. The present study focuses on the analysis of different pulse-frequencies to develop new manufacturing parameters for the industrial deposition of resistant coatings.

\section{Experimental Details}

2.1. Coating Materials and Deposition Process. The AlTiN coating deposition was performed in an industrial sized coating system "CC800/9 HiPIMS" from CemeCon AG (Würselen, Germany), equipped with a HPPMS power supply made by ADL GmbH. The HPPMS power supply is a dc-magnetron cathode operating in a pulsed mode. A rectangular sintered $\mathrm{Ti}_{0.4} \mathrm{Al}_{0.6}$-target from Plansee SE with a size of $88 \times 500 \mathrm{~mm}^{2}$ was used for the deposition process. The coating process consists of an etching and a coating phase. The etching process was performed in an argon atmosphere for the removal of thin oxide layers on the metallic substrates as well as surface activation. The coating deposition was carried out in a mixed argon (Ar), krypton $(\mathrm{Kr})$, and nitrogen $\left(\mathrm{N}_{2}\right)$ reactive atmosphere. The novel gas krypton is used for increasing the sputter rate of $\mathrm{Ti}$ - and $\mathrm{Al}$-atoms during the plasma ignition phase due to the high atom mass compared to argon and nitrogen. More details to process parameters are listed in Table 1. A constant deposition period of $30 \mathrm{~min}$ was chosen for each process parameter combination. The distance between the rectangular substrate (100Cr6-steel substrates and $\mathrm{Si}(100)$-wafer substrates with a size of $4 \mathrm{~cm}^{2}$ ) and the $\mathrm{Ti}_{0.4} \mathrm{Al}_{0.6}$-target was $70 \mathrm{~mm}$. At the stationary substrate, a constant $\mathrm{dc}$ bias voltage of $-100 \mathrm{~V}$ was applied to support film deposition and growth. To investigate the effect of different frequencies on the AlTiN coating a pulse-frequency range from $100 \mathrm{~Hz}$ to $500 \mathrm{~Hz}$ was used. The constant pulse-on-time of $50 \mu$ s has been chosen as it enables a high current density according to investigations on the effect of HPPMS pulse length with a comparable average cathode power $(5 \mathrm{~kW})$, similar process temperature $\left(500^{\circ} \mathrm{C}\right)$, and pulse-frequency $(500 \mathrm{~Hz})$ from Bobzin et al. [18]. The constant process temperature of $500^{\circ} \mathrm{C}$ and the nitrogen flow rate of $40 \mathrm{sccm}$ (nitrogen partial pressure of $83 \mathrm{mPa}$ ) were chosen to compare the current results for AlTiN coatings deposited by HPPMS with previously published results for AlTiN coatings deposited by conventional dcMS at the same average power of $4 \mathrm{~kW}$ and argon pressure of $0.6 \mathrm{~Pa}$ from Obrosov et al. [10].

2.2. Plasma and Coating Analysis. Time dependence of discharge current and voltage at the target during the deposition were monitored using a "DPO 4034 Digital Phosphor Oscilloscope" from Tektronix (USA, Beaverton). The timedependent pulse power during the HPPMS pulses $P(t)$ was calculated as product of temporal current $I(t)$ and voltage $U(t)$. Time-dependent current and power density at the target were calculated to enable a comparison with other studies using different target sizes. The film thicknesses of the AlTiN coatings deposited at different frequencies were measured with a Scanning Electron Microscope (SEM) MERLIN from Carl Zeiss Microscopy GmbH (Jena, Germany). The process deposition rates were calculated based on the constant deposition time of 30 minutes because for industrial applications the time of process for a certain film thickness is important. Hardness and elastic modulus were determined via nanoindentation with Berkovich type diamond indenter and a maximum load of $5 \mathrm{mN}$ to minimize the effect of the substrate on the measurements and to improve the precision of the instrument measurements. The nanomechanical tester called UNAT is manufactured by Asmec $\mathrm{GmbH}$ (Dresden, Germany). The quasi-continuous stiffness measurement method (QCSM) with 20 indents was used to determine the mechanical properties. Statistically averaged indention hardness as well as elastic modulus with variances were recorded for $10 \%$ of the film thickness with the control and analysis software InspektorX. The minimum coating thickness of $0.4 \mu \mathrm{m}$ was observed for $100 \mathrm{~Hz}$. The preferred $(\mathrm{Al}, \mathrm{Ti}) \mathrm{N}$ phase and crystal structure were analysed via $\mathrm{X}$ ray diffractometry (XRD) using an X-ray diffractometer "D8 Discover" from Bruker AXS GmbH (Karlsruhe, Germany) with $\mathrm{Cu}-\mathrm{K}_{\alpha 1}$ radiation $(\lambda=0.15406 \mathrm{~nm})$ in the asymmetric Bragg geometry. To avoid $2 \theta$-signals of the $100 \mathrm{Cr} 6$-substrate the chosen incident beam angle was adjusted to $\alpha=9^{\circ}$. The diffraction peaks were identified with results from powder 


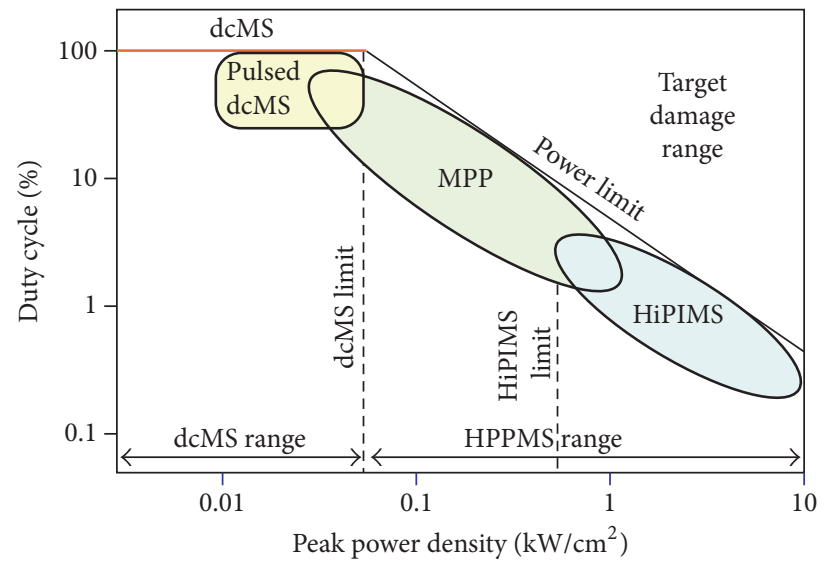

(a)

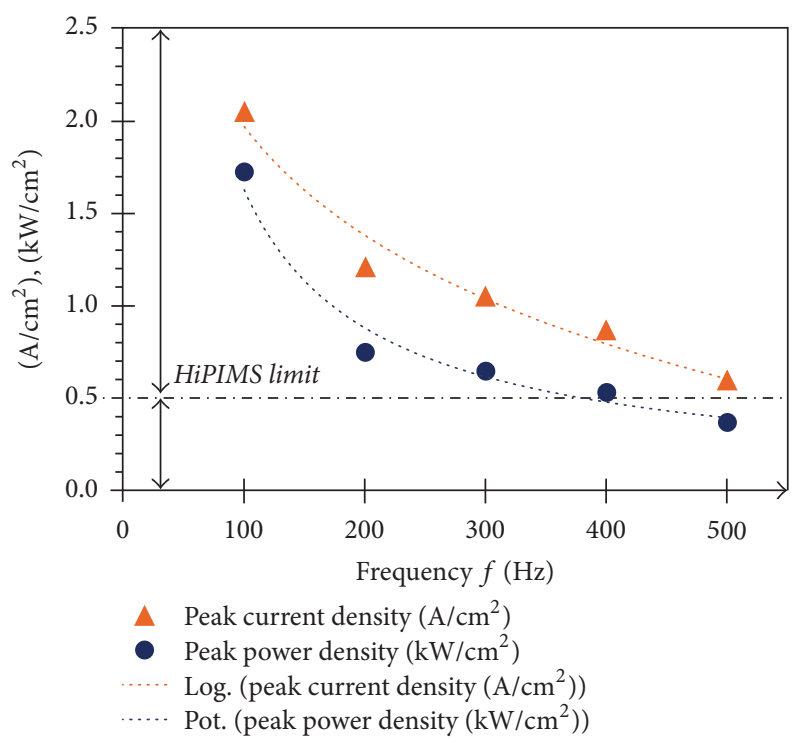

(b)

Figure 1: (a) Nomenclature for dc pulsed discharges based on the peak power density $p_{t}$ at the target, combined with the duty cycle (adapted from Gudmundsson et al. [17]). (b) Peak current density and peak power density for different frequencies in the range of 100-500 Hz measured during HPPMS discharge at a constant pulse length of $50 \mu$ s and mean power of $4 \mathrm{~kW}$ at $0.6 \mathrm{~Pa}$.

TABLE 1: Process parameters for heating, cleaning, and deposition of the (Al,Ti)N coatings in the present study.

\begin{tabular}{|c|c|c|c|}
\hline Process & Time & Parameter & Value and unit \\
\hline (1) Heating and evacuation & $90 \mathrm{~min}$ & $\begin{array}{c}\text { Heating power } \\
\text { starting pressure }\end{array}$ & $\begin{array}{c}10 \mathrm{~kW} \\
8.0 \mathrm{mPa} \\
\end{array}$ \\
\hline (2) Substrate cleaning & $30 \mathrm{~min}$ & Ion etching power & $9 \mathrm{~kW}$ \\
\hline (3) Deposition of $(\mathrm{Al}, \mathrm{Ti}) \mathrm{N}$ & $\begin{array}{l}30 \text { min (per various } \\
\text { frequency) }\end{array}$ & $\begin{array}{c}\text { Frequency } \\
\text { Duty cycle } \\
\text { Period duration } \\
\text { Pulse length } \\
\text { Mean dc cathode Power } \\
\text { Sputtering gas Pressure } \\
\text { Ar partial Pressure } \\
\text { Kr partial Pressure } \\
\mathrm{N}_{2} \text { partial Pressure } \\
\text { Temperature } \\
\text { dc bias voltage }\end{array}$ & $\begin{array}{c}100 / 200 / 300 / 400 / 500[\mathrm{~Hz}] \\
0.5 / 1.0 / 1.5 / 2.0 / 2.5[\%] \\
10.0 / 5.0 / 3.3 / 2.5 / 2.0[\mathrm{~ms}] \\
50 \mu \mathrm{s} \text { (const.) } \\
4 \mathrm{~kW} \text { (const.) } \\
0.6 \mathrm{~Pa} \text { (const.) } \\
414 \mathrm{mPa} \\
103 \mathrm{mPa} \\
83 \mathrm{mPa} \\
500^{\circ} \mathrm{C} \text { (const.) } \\
-100 \mathrm{~V} \text { (const.) }\end{array}$ \\
\hline
\end{tabular}

diffraction patterns of the ICDD database. Based on the full width at half maximum (FWHM) of each diffraction peak, the theoretical crystal sizes were calculated using the DebyeScherrer method. In addition, the elemental composition was determined by spectra of backscattered electrons with a Scanning Electron Microscope "Mira 2" from Tescan (BrnoKohoutovice, Czech Republic) with Oxford-Analysis-EDS system. The measuring parameters were $15 \mathrm{kV}$ and $2.5 \mathrm{nA}$ with a Viewfield of $2.53 \mathrm{~mm}$ and a measuring time of $120 \mathrm{~s}$. The coating structure was determined through Scanning Electron Microscope (SEM). Furthermore, details on surface quality of the AlTiN films, surface roughness, and so forth are obtained with atomic force microscopy (AFM) "Smena" and cantilever "NSG10/Pt" from NT-MDT Spectrum Instruments Ltd. (Limerick, Ireland) operating in tapping mode.

\section{Results and Discussion}

3.1. HPPMS Discharge Parameter and Plasma Properties. For a uniform nomenclature of pulsed discharge, Gudmundsson et al. [17] classified three different regimes within dcMS or HPPMS range, depending on their duty cycle and peak power density (Figure 1(a)). In particular, the specific power density referred to the target size and is beneficial for standardized comparison between the current study and other publications with different target sizes and forms. The dcMS range extends to a defined "dcMS limit" at $p_{t}=0.05 \mathrm{~kW} / \mathrm{cm}^{2}$ (Figure 1(a)) including the pulsed dcMS regime and the beginning of the modulate pulse power regime (MPP). Peak power densities higher than $0.05 \mathrm{~kW} / \mathrm{cm}^{2}$ referred to the HPPMS range, which is further categorized into MPP and 


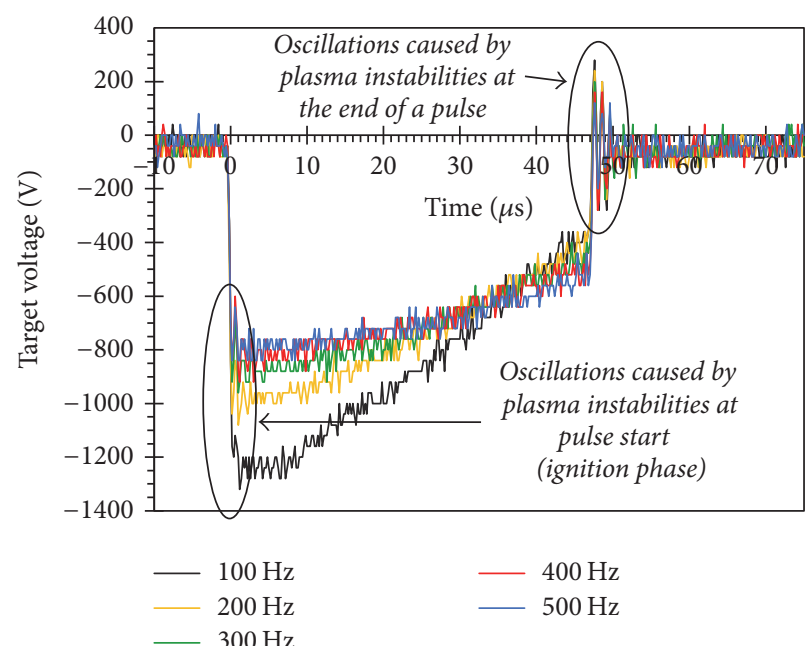

(a)

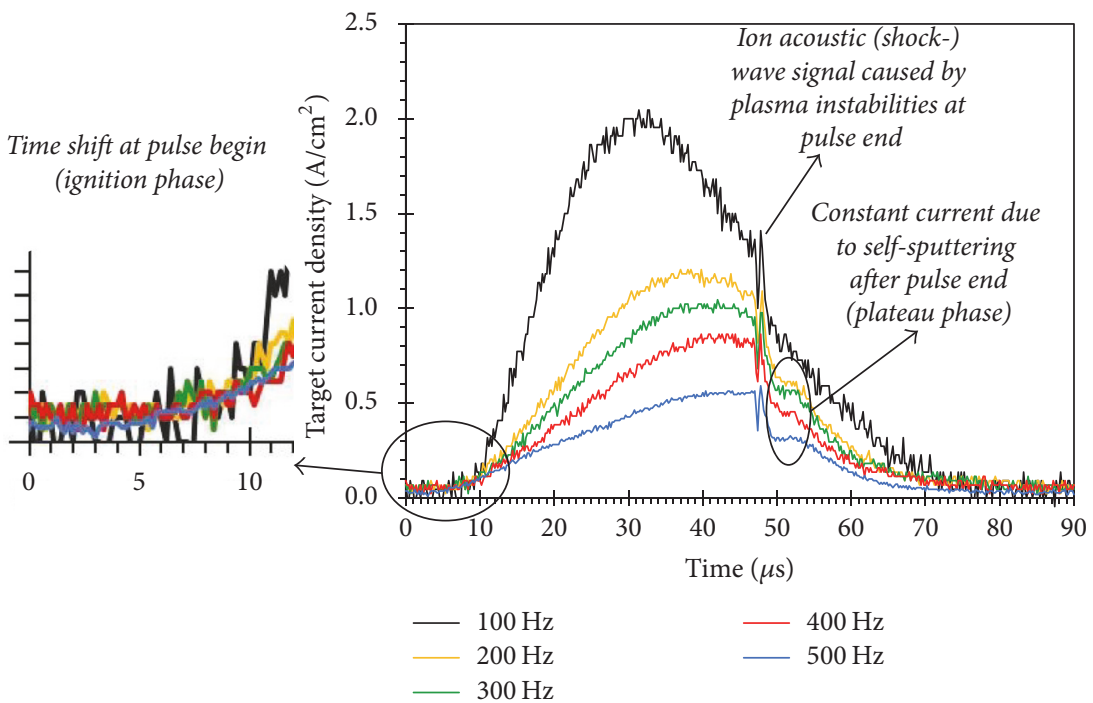

(b)

Figure 2: Time-dependent target voltages curves (a) and time-dependent current density per $\mathrm{cm}^{2}$ target surface (b) for different frequencies in the range of $100-500 \mathrm{~Hz}$ measured during HPPMS discharge at a constant pulse length of $50 \mu$ s and mean power of $4 \mathrm{~kW}$ at $0.6 \mathrm{~Pa}$.

high-power impulse magnetron sputtering (HiPIMS). The threshold between these two regimes is defined as "HiPIMS limit" with $p_{t}=0.5 \mathrm{~kW} / \mathrm{cm}^{2}$.

Based on the nomenclature, the calculated peak power density in Figure 1(b) shows that the discharge at $500 \mathrm{~Hz}$ belongs to MPP pulses with a power density below $0.5 \mathrm{~kW} / \mathrm{cm}^{2}$ (blue coloured dots). The discharges for $100-400 \mathrm{~Hz}$ belong to the HiPIMS range with high-power densities above $0.5 \mathrm{~kW} / \mathrm{cm}^{2}$ and short duty cycles. All considered discharges for this study took place below the defined "power limit" and the "target damage range."

Generally, the target voltage represents the electrical potential where ions and electrons are accelerated whereas the time-dependent discharge current density (plasma density) corresponds to the number of ions and electrons in the plasma. Due to these facts, the current pathways indicate the ionization of metal ions and the discharge behaviour, like discharge phases or plasma instabilities. Moreover, the timedependent pulse power density is an indication of the plasma species energy and the thermal load at the target during the pulse-on-time.

Increasing pulse-frequency (as well as duty cycle) shows a decreasing potential trend for peak current density and peak power density (Figure 1(b)). This behaviour results from a lower plasma resistance with increasing frequency, which leads to a lower ignition voltage at the target (Figure 2(a)). The lower voltages (electrical potential for acceleration) provoke less ionization rates, resulting in a decreased current density (Figure 2(b)).

In the case of an industrial coater, it has to be considered that measured voltage and current waveforms are determined by the size of the capacitor bank used within the power unit [19]. 
In particular the decrease of the voltage during pulse-ontime due to decreasing plasma resistance and increasing discharge current can be avoided with an additional control system. Generally, every pulse starts with an ignition phase when the negative voltage is applied to the target and the ionization of the working gas begins. The discharge will likely ignite as a localized glow discharge at the target in the vicinity of the anode ring, where the vacuum electric field is strongest [20]. This improves the ionization of the working gas species and the number of charge carriers increases. If enough working gas ions and energetic electrons are available due to an increasing amount of collisions, the plasma completely ignites. After bulk plasma breakdown, the discharge current increases rapidly until a current maximum is reached combined with a decrease in voltage. In this current rise phase, a dense plasma torus is developed above the target race track [20] and the metal atom density builds up due to sputtering of the working gas ions. With increasing number of metal atoms, Penning ionization of the sputtered vapour atoms as well as electron impact ionization of neutral gas atoms increases [21]. For this reason, the current rise is dominated by metal ions, which accelerate back to the target and take part in sputtering process [17]. This resputtering of target occurs if the ions possess enough energy to knock out new target atoms. In contrast, the working gas is affected by gas-rarefaction due to the thermal expansion and a slow refill process of neutral gas atoms into the ionization region in the target vicinity takes place $[22,23]$. At the moment of peak current, the maximum number of metal ions with the highest possible ion energies is achieved [18, 24, 25]. Compared to other investigations of ion distributions in Argon HPPMS-plasma with $\mathrm{Ti}$ and $\mathrm{Al}$, where current and power densities were similar to those in this study, it can be assumed that the plasma at all selected pulse-frequencies consists of single- and multiple-charged $\mathrm{Ti}$ and $\mathrm{Al}$ ions [24, 26]. After the maximum peak current is achieved, the gasrarefaction generally becomes dominating and the current decreases as the number of sputtering ions decreases due to lower degree of ionization. This decreasing current phase is characterized by a decreasing number of high energetic multiple-charged metal ions and an increasing number of neutral target atoms. In this study, the current decrease exclusively occurs at low frequencies $(100 \mathrm{~Hz}$ and $200 \mathrm{~Hz})$ due to the high ionization rates. The ionization rate depends on the electrical potential (target voltage) and is represented by the rise of the discharge current. A steep current rise like the one at a low pulse-frequency of $100 \mathrm{~Hz}$ stands for a high ionization rate. In contrast, a lower current rise for higher frequencies indicates a lower ionization rate. This behaviour affects the time of peak current density along with the time shift of the current maximum as shown for higher frequencies (Figure 2(b)). For all frequencies, the HPPMS pulses end when the voltage is rapidly switched off at $50 \mu \mathrm{s}$. This sharp drop of voltage leads to plasma instabilities (Figure 2(a)) and causes an ion shockwave (ion acoustic wave) which appears at the end of current waves (Figure 2(b)). Apart from this, no overshoots after the pulse-off were generated. More details to plasma instabilities during HPPMS deposition are discussed by, for example, Sarakinos et al. [13], Maszl et al. [26], or
Breilmann et al. [27]. Subsequent to this instable phase, the discharge at a pulse-frequency of $200-500 \mathrm{~Hz}$ passes into a plateau phase where self-sputtering processes sustain the discharge for a few $\mu$ s. This constant current density (plateau phase) occurs when a significant fraction of ions with high potential energy generates fast secondary electrons which can sustain the impact ionization [17]. These ions are mostly double ionized metal atoms [17]. For AlTiN deposition, we assumed that $\mathrm{Ti}^{2+}$ dominates the self-sputtering due to lower second ionization energy of titanium in comparison to aluminium [28]. The missing plateau phase at $100 \mathrm{~Hz}$ indicates that the conditions for self-sputtering after voltage switch-off are not fulfilled due to the strong gas-rarefaction between pulse maximum and pulse end. At the end of the plateau phase in case of 200 to $500 \mathrm{~Hz}$ and after voltage switch-off in case of $100 \mathrm{~Hz}$, the discharge shifts into the afterglow phase. This phase is characterized by a sharp drop down of current due to the loss of plasma species in the target vicinity through recombination and diffusion towards the substrate and chamber walls [21].

These measurements demonstrate that the target current density and the target ignition voltage decrease, if the pulsefrequency increases from $100 \mathrm{~Hz}$ to $500 \mathrm{~Hz}$ at a constant pulse length. The appearance of plasma instabilities at the beginning and at the end of a pulse seems to be independent of the frequency (see Figure 2(a)). This fact indicates that oscillations are connected with pulse transient phenomena and the plasma decaying during the pulse-off-time. Due to these oscillations, also the sheath potential $U_{\mathrm{Sh}}=U_{P}-$ $U_{S}$ in front of the substrate oscillates and in maxima of these oscillations the growing film is bombarded by ions with higher energy. Here $U_{P}$ is the plasma potential and $U_{S}$ the constant substrate bias of $-100 \mathrm{~V}$. Exclusively the size of oscillations due to plasma instabilities increases for higher current densities at lower frequencies. Self-sustained, selfsputtering processes occur only at higher frequencies, if the discharge reaches its peak current close to the end of a HPPMS pulse. However, by reducing the pulse-frequency, a higher ionization rate of sputtered $\mathrm{Ti}$ - and $\mathrm{Al}$-atoms resulting in an increased metal ion bombardment of the substrate can be expected.

3.2. Film Thickness and Deposition Rate. Figure 3(a) shows the calculated deposition rate of AlTiN coatings deposited at various pulse-frequencies as a quotient of the measured film thickness and the constant deposition time of 30 minutes. These results show a linear increasing correlation between deposition rate (as well as film thickness due to constant deposition time) and pulse-frequency. Hence, the deposition rate increases proportionally with the pulse-frequency due to the increased time of sputtering resulting in a higher material deposition at a constant sputtering process time. Long offtimes between two pulses, as in the case at $100 \mathrm{~Hz}$ with a pulse duration of $T=10 \mathrm{~ms}$, correspond to less sputtering effects of target material. Figure 3(b) shows the decreasing deposition rate in relation to the increasing peak current density at lower frequencies. In comparison to deposition rates with dc-magnetron sputtering at the same average cathode power, 


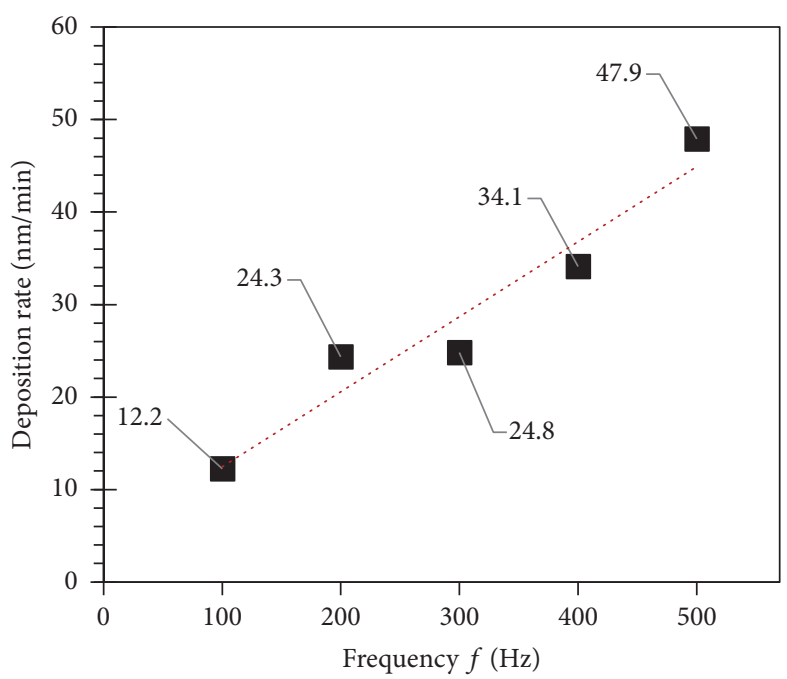

(a)

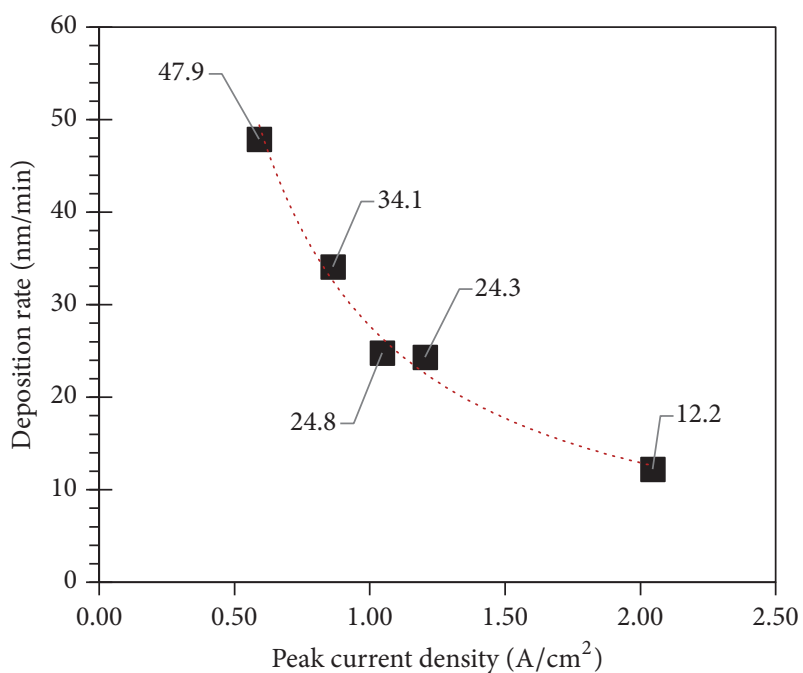

(b)

FIGURE 3: Deposition rate of the AlTiN coatings depending on pulse-frequency (a) and on the resulting peak current density (b) at different pulse-frequencies in the range of $100-500 \mathrm{~Hz}$ with a constant pulse length of $50 \mu$ s and deposition time of 30 minutes.

the HPPMS deposition rate is reduced, as shown for various materials $[29,30]$. An explanation for the reduction in deposition rate is the target material pathways model from Christie [31], which allows calculating the fraction of the ionized sputtered vapour returning to the target, the degree of ionization of the sputtered vapours, and the ionized flux fraction onto the substrate. Generally, a higher amount of metal ions increases the probability for backattracted ionized Ti- and Al-atoms at the target. Additionally, Emmerlich et al. [32] argued that no comparison between HPPMS and dcMS deposition rates for the same average cathode power is possible, if the nonlinear energy dependence of the sputtering yield is not taken into account.

3.3. Elemental Composition. The elemental composition of the AlTiN coatings in Figure 4 shows the relation between the $\mathrm{Al}, \mathrm{Ti}$, and $\mathrm{N}$ content of sputtered AlTiN coatings with different pulse-frequencies in the range of $100-500 \mathrm{~Hz}$. The averaged result of the detected spectra shows a $20 \%$ increase of the $\mathrm{Al}$ content with higher pulse-frequencies, while the nitrogen concentration decreases significantly. This is represented by the stoichiometry $x=\mathrm{N} /(\mathrm{Al}+\mathrm{Ti})$ in Table 2 as well. In relation to the report of Musil [33], the overstoichiometric $(x>1)$ AlTiN coatings sputtered at low frequencies $(100,200 \mathrm{~Hz})$ show that the delivered energy by bombarding ions during the film growth increases as the frequency decreases. Whereas the substoichiometric $(x<1)$ AlTiN coatings sputtered at 300,400 , and $500 \mathrm{~Hz}$ show a decreasing delivered energy by bombarding ions for increasing frequency.

In contrast to the altered $\mathrm{Al}$ and $\mathrm{N}$ content, the $\mathrm{Ti}$ concentration is nearly constant and fluctuates between $24 \%$ and $28 \%$, whereby the highest Ti content in the sputtered AlTiN coatings was measured for $300 \mathrm{~Hz}$. For this reason,

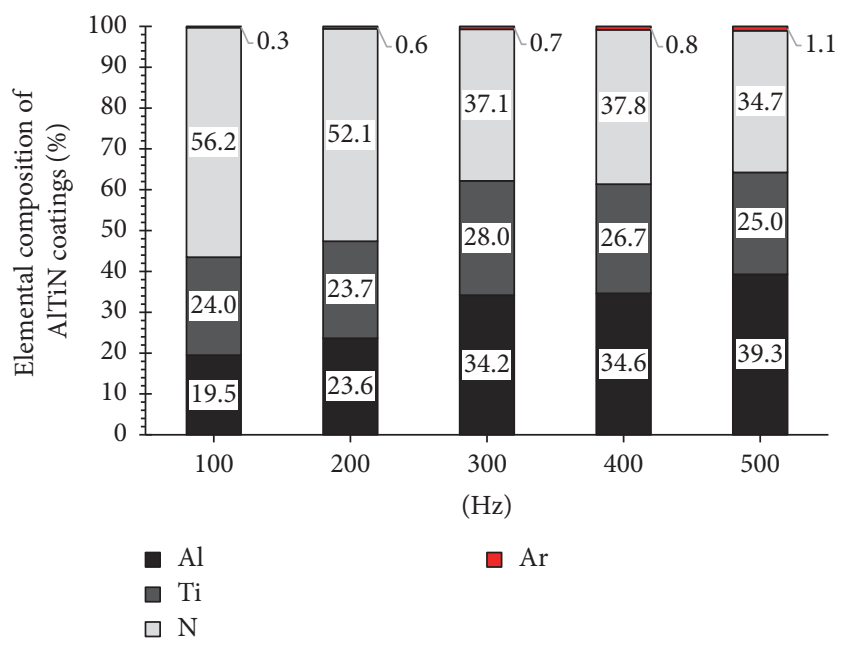

FIGURE 4: Elemental composition of AlTiN coatings by HPPMS with various pulse-frequency in the range of $100-500 \mathrm{~Hz}$.

the most uniform distribution of $\mathrm{Al}, \mathrm{Ti}$, and $\mathrm{N}$ content in this study was achieved at $300 \mathrm{~Hz}$. Furthermore, the concentration of Ar is included in Figure 4 for showing the incorporation of process gas atoms as impurity atoms during film growth. The results show that, for higher Al concentrations with increasing frequency (decreasing pulse power density), the Ar content increases from $0.3 \%$ up to $1.1 \%$, which is negligible for this study. Thus, an increasing Ar content leads to a higher probability of defects and imperfections in the coating structure due to lattice disruptions during the lattice formation. The reversed behaviour of nitrogen and aluminium content indicates a direct relationship between both elements and the pulse-frequency as well as the resulting deposition conditions. As the elemental composition shows, 
TABLE 2: Elemental composition and stoichiometry of the (Al,Ti) N coatings at different pulse frequencies.

\begin{tabular}{lcccc}
\hline Pulse frequency & \multicolumn{2}{c}{ Elemental composition [at. \%] } & Stoichiometry \\
& $\mathrm{Al}$ & $\mathrm{Ti}$ & 56.22 & $x=\mathrm{N} /(\mathrm{Al}+\mathrm{Ti})$ \\
\hline $100 \mathrm{~Hz}$ & 19.49 & 23.98 & 52.05 & 1.293 \\
$200 \mathrm{~Hz}$ & 23.65 & 23.73 & 37.11 & 0.099 \\
$300 \mathrm{~Hz}$ & 34.18 & 27.99 & 37.80 & 0.597 \\
$400 \mathrm{~Hz}$ & 34.64 & 26.73 & 34.70 & 0.616 \\
$500 \mathrm{~Hz}$ & 39.29 & 24.96 & 0.540 \\
\hline
\end{tabular}

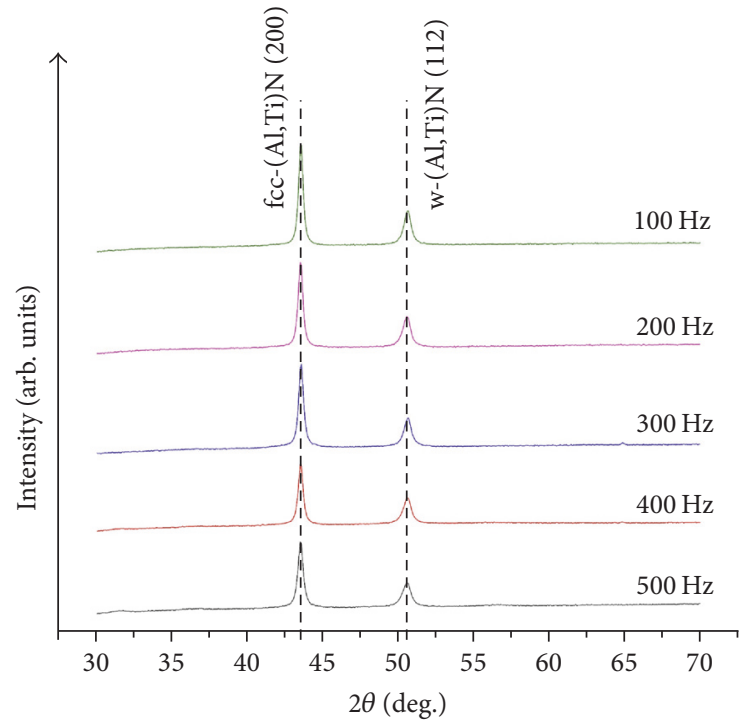

FIGURE 5: 2-theta XRD-measurements of fcc- and w-AlTiN phases of AlTiN coatings by HPPMS with various pulse-frequency in the range of $100-500 \mathrm{~Hz}$.

the amount of $\mathrm{N}$ in the AlTiN coatings increases with lower frequencies due to an increased pulse-off-time, which leads to a preferred incorporation of reactive nitrogen into the growing film lattice provoked by the constant substrate bias of $-100 \mathrm{~V}$ and a chamber temperature of $500^{\circ} \mathrm{C}$. In contrast, the longer pulse-off-time causes an increased loss of $\mathrm{Al}$ in a nitride layer at the target (target poisoning), resulting in a decreased $\mathrm{Al}$ content in the coating at lower frequencies.

3.4. AlTiN Phase Analysis. In Figure 5 the XRD patterns of $(\mathrm{Al}, \mathrm{Ti}) \mathrm{N}$ coatings deposited from a $\mathrm{Ti}_{0,4} \mathrm{Al}_{0,6}$ target at different pulse-frequencies show a two-phase structure with a dominant face-centred cubic AlTiN (200) phase at $2 \theta=43.5^{\circ}$ and a less pronounced wurtzite-type AlTiN (112) phase at $2 \theta$ $=50.6^{\circ}$ for all AlTiN coatings. The clearly separated phase reflections implicate an AlTiN coating composition with a mixture of fcc- and w-AlTiN phase grains. Thereby, the fccAlTiN grains represent the main phase due to the higher relative signal intensities compared to the relative intensities of the w-AlTiN phase. In connection with the nonstoichiometric behaviour, shown in Section 3.3, a substitutional solid solution of $\mathrm{Al}, \mathrm{Ti}$, and $\mathrm{N}$ in the face-centred cubic crystal lattice and in the wurtzite-type lattice can be assumed. The relative proportion of both phase signal intensities reflects the increasing $\mathrm{Al}$ content and decreasing $\mathrm{N}$ concentration with increasing frequency. While the relative intensity of the fcc-AlTiN phase signal decreases, the relative intensity of the w-AlTiN phase signal increases. So, the increasing amount of nitrogen at lower frequencies is primarily incorporated into the fcc-AlTiN phase and sustains the formation of fcc lattice structure due to diffusion processes or nitride layer formation. The peak shift of the fcc-phase towards higher $2 \theta$ angles caused by lattice contraction due to $\mathrm{Al}$ incorporation into a preferred fcc-TiN lattice proves the assumption of substitutional solid solution and preferential phase formation, too. In contrast, the increased $\mathrm{Al}$ concentration and reduced nitrogen content at higher frequencies lead to a less pronounced fcc-AlTiN signal and support the w-AlTiN formation. Here, the proximity of the hexagonal AlN and tetragonal TiN signal to the detected w-AlTiN (112) phase peak confirms the assumption of substitutional solid solution. Thereby, the peak shift towards hexagonal AlN results from incorporation of $\mathrm{Ti}$ into the hexagonal AlN lattice during film growth. Such a formation of a w-AlTiN phase for AlTiN coatings deposited with cathodic-arc evaporation was also shown by Rafaja et al. [34]. Since the arc process is characterized by a high ion bombardment and temperature input of the growing layer, the phase formation is comparable with the HPPMS process conditions in this study. Rafaja et al. [34] argued that the Al-rich titanium aluminium nitride forms apparently w-AlTiN instead of fluctuation of the $\mathrm{Al}$ and Ti concentration within fcc-TiAlN or instead of forming fccAlN or w-AlN.

In addition, the formation of wurtzite-type AlTiN phases partly results from energetic bombardment of $\mathrm{Ti}^{2+}$ ions during film deposition. Large ion fluxes of $\mathrm{Ti}^{2+}$ result in high values of incident metal ion energy $\left(E_{d}\right)$ and momentum transfer $\left(p_{d}\right)$ per deposited metal atom and give rise to point defects. These defects can result in the formation of relatively soft wurtzite-structure AlN in form of secondphase precipitates, leading to poor mechanical properties $[35,36]$. As already mentioned, no separate w-AlN phases were detected in the current study and therefore no w-AlN precipitation occurs.

Rafaja et al. [34] determine that the nanocomposite consisting of fcc-and wurtzite-phases seems to be stable until $650^{\circ} \mathrm{C}$, despite the relatively high $\mathrm{Al}$ concentration in the coating. These facts indicate that the substrate temperature at different pulse-frequencies does not exceed $650^{\circ} \mathrm{C}$. However, 
TABLE 3: Identified $2 \theta$-position from the peak intensity of fcc-AlTiN phases and w-AlTiN phases at various pulse frequencies in the range of $100-500 \mathrm{~Hz}$.

\begin{tabular}{lcc}
\hline Pulse frequency & & Diffraction peak angle 2 \\
& fcc-AlTiN (200) & $50.60^{\circ}$ \\
$100 \mathrm{~Hz}$ & $43.55^{\circ}$ & $50.55^{\circ}$ \\
$200 \mathrm{~Hz}$ & $43.50^{\circ}$ & $50.60^{\circ}$ \\
$300 \mathrm{~Hz}$ & $43.50^{\circ}$ & $50.60^{\circ}$ \\
$400 \mathrm{~Hz}$ & $43.50^{\circ}$ & $50.60^{\circ}$ \\
$500 \mathrm{~Hz}$ & $43.50^{\circ}$ & w-AlTiN (112) \\
\hline
\end{tabular}

in this study substrate and growing film are additionally heated during the whole deposition process by the determined constant process temperature of $500^{\circ} \mathrm{C}$. Besides this fact, the substrate temperature increases during pulse-ontime due to the high input of thermal energy caused by thermalized electrons in the substrate bias and ion impact heat transfer to the growing film. During the pulse-offtime, substrate and growing film can cool down so that the normalized heat transfer to the substrate is lower in HPPMS compared to dcMS at the same average power [37], even though the energy flux per deposited particle is higher for a HPPMS discharge. If the pulse-frequency increases, the pulse-off-time decreases and causes a reduction of cooling time.

Besides this, in this study the formation of a clearly twophase structure of fcc- and w-AlTiN grains is independent of the pulse-frequency and the resulting discharge parameters. This shows that discharge properties are similar due to the identical pulse length of $50 \mu \mathrm{s}$, which causes comparable discharge phases during pulse-on-time. (As discussed in Section 3.1., all discharges take place in HPPMS mode and reach a peak power density close to or even inside the HiPIMS mode defined by Gudmundsson et al. [17].) As an addition to this observation, the constant two-phase structure implicates that the time of discharge and the discharge phases, from ignition phase to afterglow phase at pulse end, have a stronger influence on the formation of various AlTiN phases than different pulse-frequencies. One reason is the transition from HPPMS mode to dcMS-like mode as described previously [35], which causes a change in plasma characteristics referring to the sputtered metal ion-to-neutral ratio. For HPPMS mode, this metal ion-to-neutral ratio is very high and depends on pulse current and power density, whereas the dcMS-like mode is dominated by neutral sputtered atoms and less metal ions.

As a result of the discharges mode, face-centred cubic AlTiN grains with strong 200-reflection intensities were detected, which are typical for AlTiN HPPMS coatings as referred by other authors [15, 35]. (In contrast, dcMS films show a highly 111-oriented fcc-AlTiN structure due to the dominance of neutral sputtered metal species [15].) Furthermore, it is known for transition-metal nitrides that the 200-orientation is energetically favourable in the rock salt-type structure [38-40] and leads to a higher hardness due to a denser lattice structure than 111-oriented fcc-AlTiN, which is advantageous for cutting tool coatings. The absence of an fcc-AlTiN (111) phase shows that no dcMS-like discharge conditions were reached. In conformity with Ehiasarian et al. [41], composition and energy of the impinging ions define the surface chemistry on crystal faces as well as the adatoms mobility on the surface during film growth. Especially the presence of atomic nitrogen and ionized metal species with a broad IEDF (Ion Energy Distribution Function) promote the growth of (200)-orientation and suppresses the growth of (111)-oriented crystals [41]. In this case, the dissociation of molecular nitrogen to atomic nitrogen takes place on the target and in its vicinity due to the high current and power density at the target. Detailed descriptions to ions origin, metal ion energies (IEDF) and behaviour of the metal ion flux in HPPMS discharges can be found in several publications, for example, from Gudmundsson et al. [17] and Bohlmark et al. [24].

The only difference at various pulse-frequencies is a peak shift of $0.05^{\circ}$ for the fcc-AlTiN (200) phase at $100 \mathrm{~Hz}$ and the w-AlTiN (112) phase at $200 \mathrm{~Hz}$ as listed in Table 3. In both cases, the shift results from internal coating stresses caused by different electrical discharge conditions, because high current densities lead to a high ion bombardment at the substrate, resulting in higher internal stress due to a higher probability of residual defect formation [42].

3.5. Grain Sizes and Coating Structure. Based on the FWHM from the detected AlTiN phase reflexes, the grain sizes of cubic and wurtzite-type AlTiN phase were determined using the Debye-Scherrer formula. This method provides the smallest measurable size of a crystal structure of the same orientation and is sufficiently accurate to describe a tendency for different pulse-frequencies as it is shown in Figure 6. The results in Figure 6(a) show that the grain size of the cubic AlTiN phase in (200)-orientation is always larger than the one of the wurtzite-type grains in (112)-orientation. However, the size of both grain orientations shows a decreasing linear trend for higher frequencies. Generally a decreasing grain size refers to an increasing volume fraction of grain and phaseboundaries, so that the coating properties are increasingly influenced by the interfacial components [43]. According to Messier et al. [44] an increased ion bombardment causes a dense, coaxial structure and increases the nucleation density by forming nucleation locations like defects, implanted, and resputtered species. With an increasing number of preferential nucleation sites, the decreasing grain size can be attributed to the higher energy incident ions at higher frequencies. This leads to the generation of more defects 


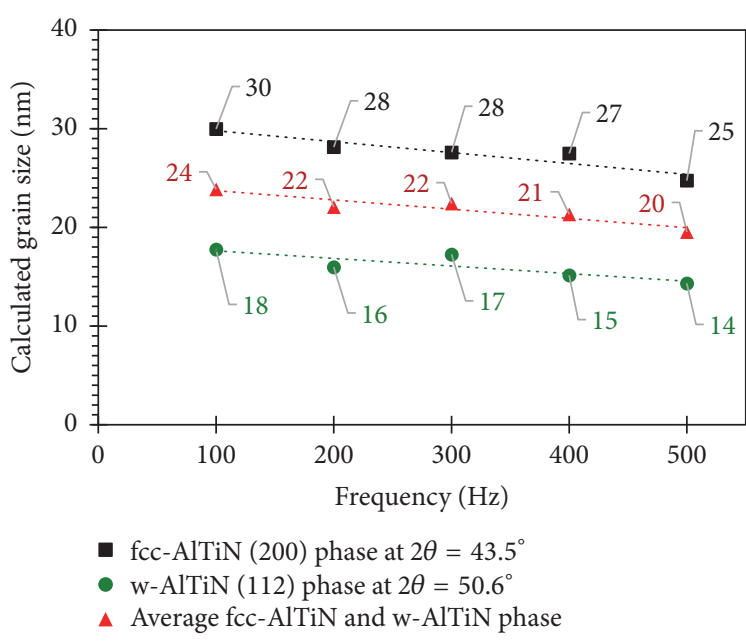

(a)

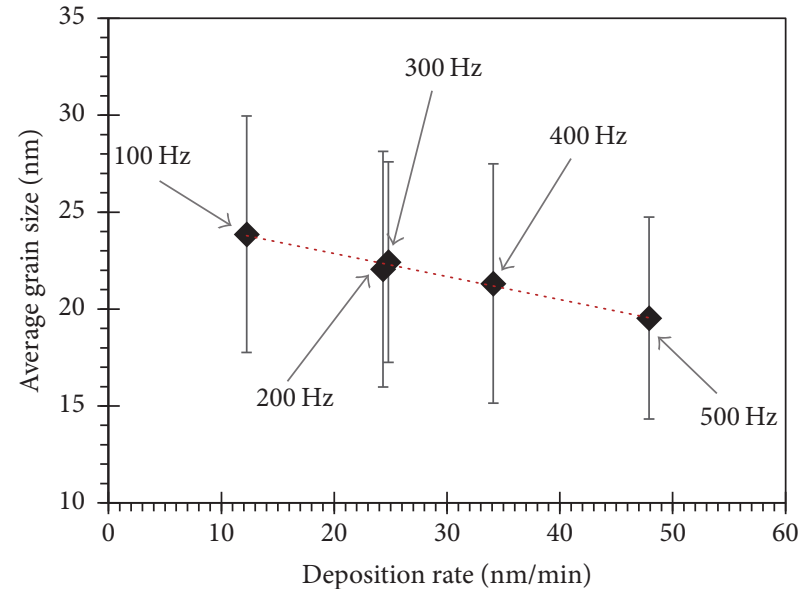

(b)

Figure 6: Calculated grain size by Debye-Scherrer formula and linear regression functions (a) of the fcc-AlTiN phases (black data points), the w-AlTiN phases (green data points), and the averaged grain size of both phases (red data points). (b) shows the average grain size of fcc-AlTiN and w-AlTiN as a function of the deposition rate at different pulse-frequencies in the range of $100-500 \mathrm{~Hz}$.

on the surface of the growing film, as reported from Sundgren [45]. Additionally, thermal energy applied into the surface region increases the surface mobility of adatoms and promotes reactions as well as diffusion processes [46]. As mentioned in Section 3.4., the high constant substrate temperature of minimum $500^{\circ} \mathrm{C}$ causes that the substrate heating during pulse-on-time and its rise with increasing frequency is negligible in this consideration.

Based on the above-mentioned facts, it is assumed that the decreasing grain size with increasing frequency is related to the increasing layer thickness and defect density (Figure 6(b)). An indication for this relation is the comparable deposition rate at $200 \mathrm{~Hz}$ and $300 \mathrm{~Hz}$, which leads to similar grain sizes. As a consequence, a higher coating thickness leads to an increased probability of growth disturbance and defect density due to more frequent energetic ion bombardment within the constant deposition time of 30 minutes. This also gives rise to renucleation with competitive growth of grains resulting in smaller grain size. Particularly this competition during the growth of the fcc-and w-AlTiN phases is enhanced due to different preferred growth directions and lattice structures [42].

The cross-sectional SEM images in Figures 7-11 show the AlTiN coating structure as deposited on 100Cr6-steel and silicon substrates with different pulse-frequencies. All AlTiN coatings show a dense and fine nanostructure with slight differences in crystal size, porosity, and growth direction, which probably causes differences in their mechanical properties. Based on the structural zone model (SZM) of sputtered metallic films developed by Thornton [47] and the process parameter in this study, it can be concluded that the deposited AlTiN coating structure belongs to zone T. However, the coating structure of the AlTiN coatings becomes coarser with increasing pulse-frequency due to a higher defect density. Further, the increasing frequency results in a shorter pulse-off-time in which impurities, foreign atoms, or lattice imperfections are removed by resputtering effects induced by the substrate bias of $-100 \mathrm{~V}$. The shorter pulse-off-time reduces the period for refilling gaps in the growing coating structure, which is favoured by the high process temperature of $500^{\circ} \mathrm{C}$. This is confirmed by results from Rafaja et al. [34], who reported that, at high stacking fault densities, facilitated by high local $\mathrm{Al}$ concentrations, the faulted fcc-TiAlN changes to w-AlTiN. So, AlTiN coatings deposited by HPPMS generally show a denser and smoother structure without column growth than coatings deposited by dcMS at the same average power due to increased metal ion bombardment [15]. This is confirmed by comparing the coating structure with published results from Obrosov et al. [10]. Such a dense featureless, feathery coating structure is typical for coatings deposited with pulsed magnetron sputtering as, for example, Keunecke et al. [48] and Jílek Jr. et al. [49] have shown. The bombardment and inclusion of droplets, as shown in Figure 7(b), induced growth disturbances and structure disorders during coating deposition. Those disturbances cause internal stresses in the vicinity of the droplet and can promote coating chipping or failure, especially under load conditions during cutting or forming processes.

3.6. Mechanical Properties. Hardness and elastic modulus of deposited AlTiN layer are reference factors in order to assess the properties and thus the suitability of wear protection coatings. In addition, they are beneficial to compare the coating properties achieved through HPPMS with the ones of other PVD technologies, such as dcMS or cathodic-arc 


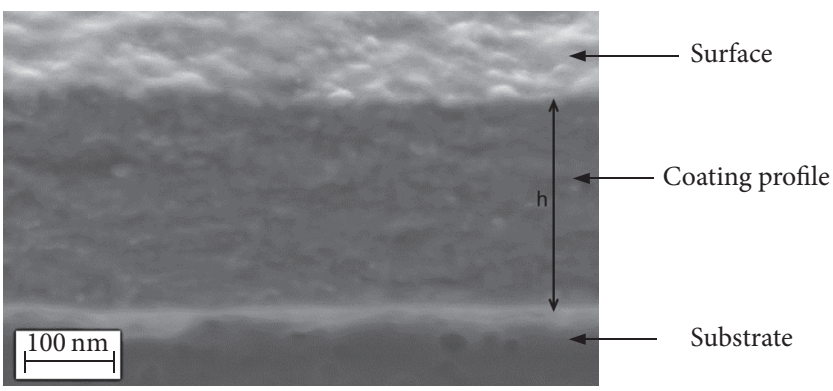

(a)

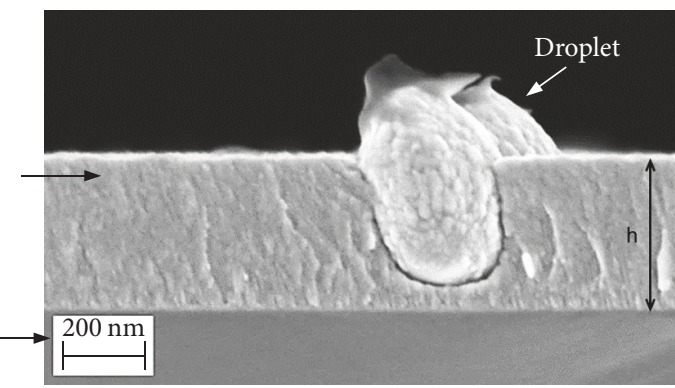

(b)

Figure 7: Cross-sectional SEM images of AlTiN coatings deposited at $100 \mathrm{~Hz}$ on 100Cr6-steel substrate (a) and silicon substrate (b) with film thickness $h=0.366 \mu \mathrm{m}$.

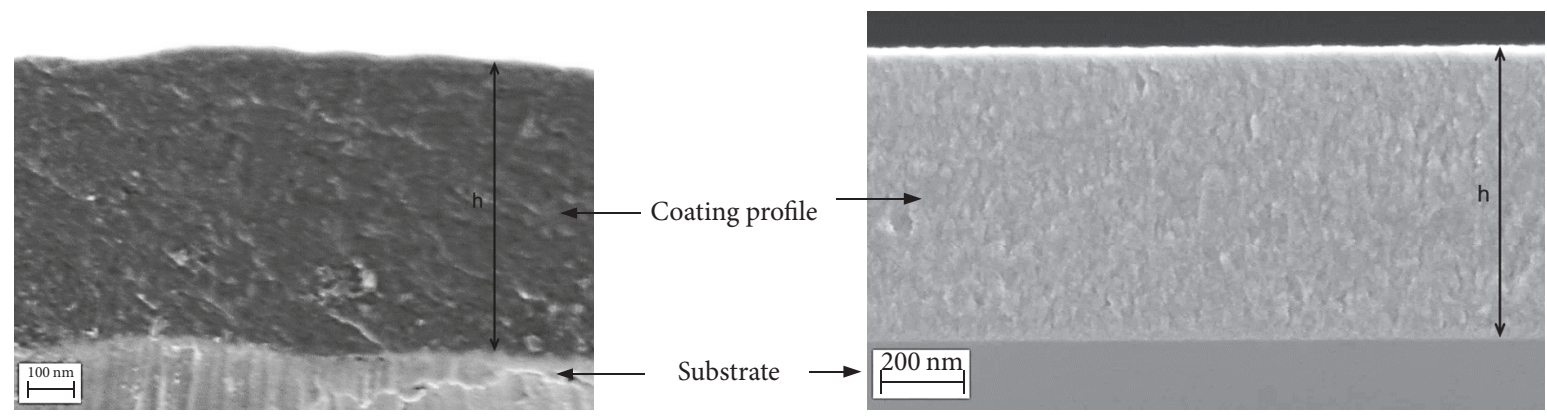

(a)

(b)

FiguRE 8: Cross-sectional SEM images of AlTiN coatings deposited at $200 \mathrm{~Hz}$ on 100Cr6-steel substrate (a) and silicon substrate (b) with film thickness $h=0.729 \mu \mathrm{m}$.

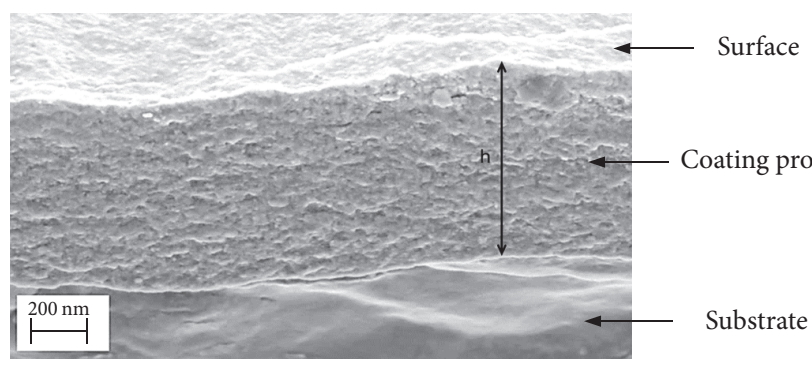

(a)

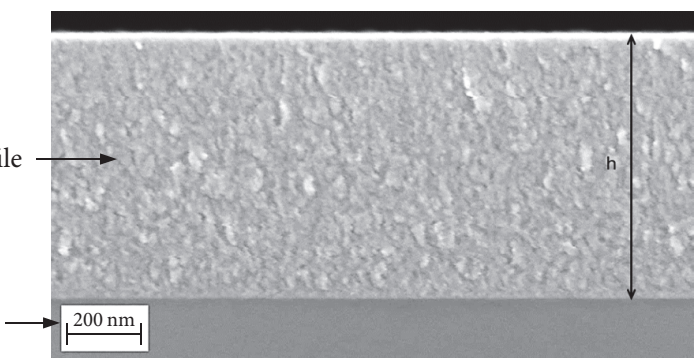

(b)

Figure 9: Cross-sectional SEM images of AlTiN coatings deposited at $300 \mathrm{~Hz}$ on 100Cr6-steel substrate (a) and silicon substrate (b) with film thickness $h=0.744 \mu \mathrm{m}$.

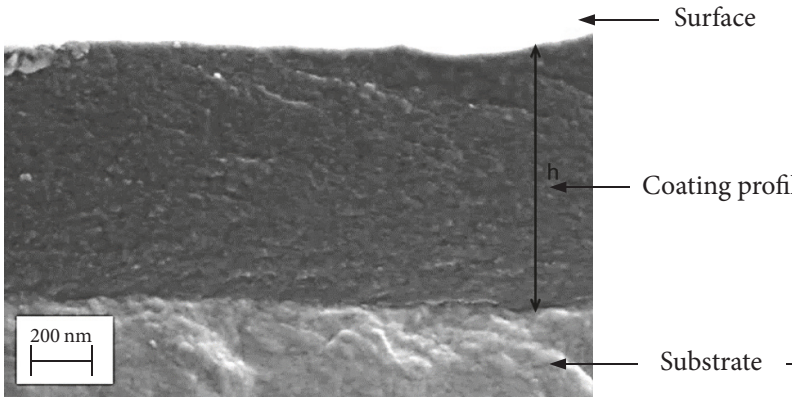

(a)

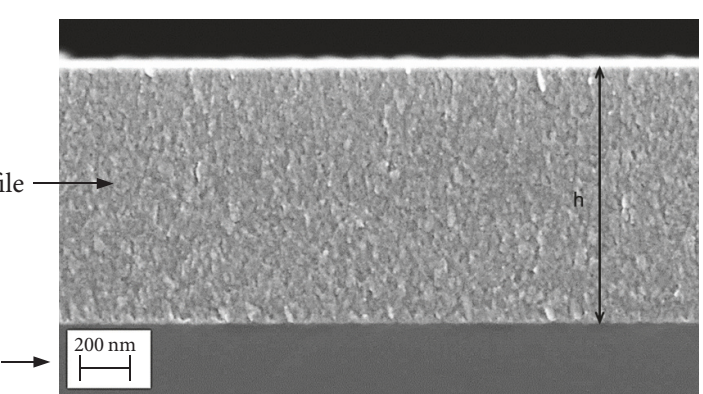

(b)

FIGURE 10: Cross-sectional SEM images of AlTiN coatings deposited at $400 \mathrm{~Hz}$ on 100Cr6-steel substrate (a) and silicon substrate (b) with film thickness $h=1.023 \mu \mathrm{m}$. 


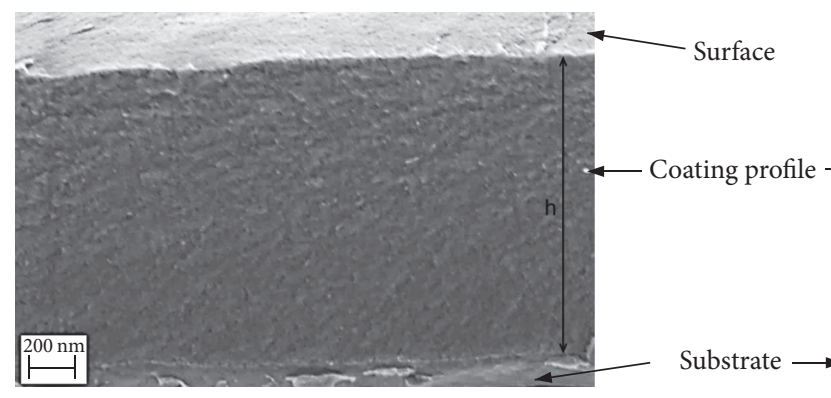

(a)

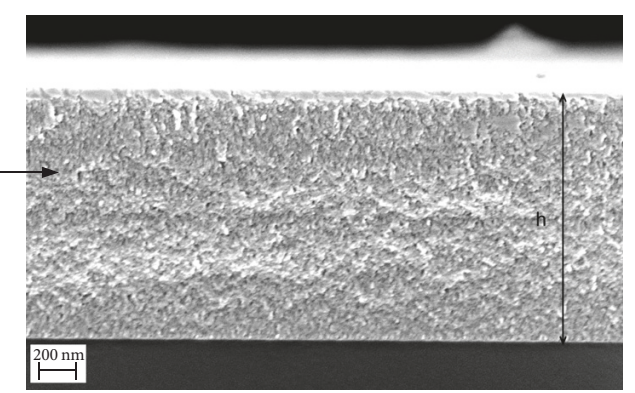

(b)

FIGURE 11: Cross-sectional SEM images of AlTiN coatings deposited at $500 \mathrm{~Hz}$ on 100Cr6-steel substrate (a) and silicon substrate (b) with film thickness $h=1.437 \mu \mathrm{m}$.

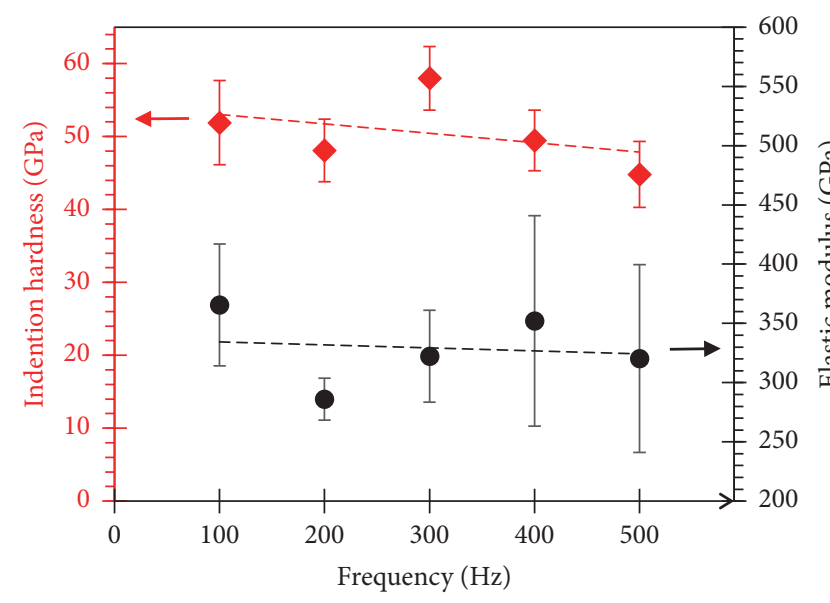

(a)

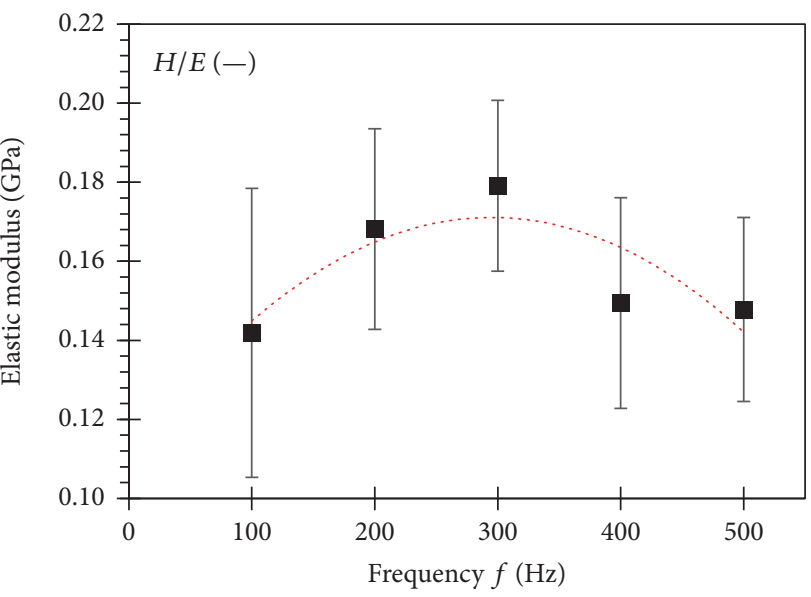

(b)

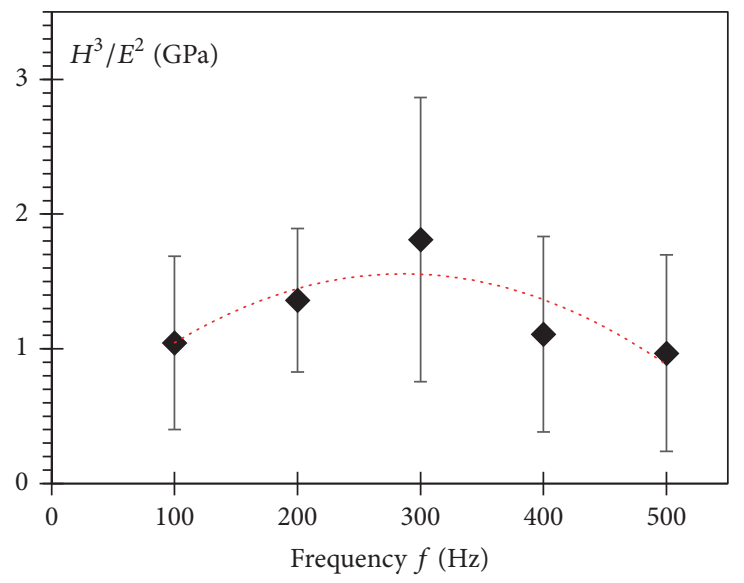

(c)

FIGURE 12: Mean indention hardness and elastic modulus with standard variance in GPa (a), calculated resistance against elastic deformation (elastic strain to failure) (b), and plastic deformation (c) of AlTiN coatings deposited by HPPMS with various pulse-frequency in the range of $100-500 \mathrm{~Hz}$ at cathode mean power of $4 \mathrm{~kW}$, pressure of $0.6 \mathrm{~Pa}$, and deposition temperature of $500^{\circ} \mathrm{C}$.

evaporation. In this study, a relationship between indention hardness and elastic modulus with increasing pulsefrequency is focused. The averaged results of the QCSM measurements in a depth of around $10 \%$ of the film thickness in Figure 12(a) show a hardness of more than $40 \mathrm{GPa}$ and elastic moduli between $290 \mathrm{GPa}$ and $350 \mathrm{GPa}$. Thus, the deposited AlTiN coatings belong to superhard coatings with low elastic moduli. In comparison, AlTiN films deposited by dcMS from Obrosov et al. [10] reach a hardness of $21.5 \mathrm{GPa}$ with elastic modulus of $238 \mathrm{GPa}$ at the same average power, 
process temperature, and nitrogen flow rate. For different process conditions, AlTiN films deposited by dcMS from Jílek Jr. et al. [49] reach a hardness of 33.4 GPa with elastic modulus of $466 \mathrm{GPa}$. Similar hardness $(33.9 \mathrm{GPa})$ and a higher elastic modulus of $550 \mathrm{GPa}$ were measured from Nohava et al. [50] for arc evaporated AlTiN coatings. One reason for differences in mechanical properties between AlTiN coatings deposited by dcMS, arc evaporation, or HPPMS are the different plasma conditions during deposition. These different plasma properties influence the film microstructure as well as the AlTiN phase formation, which can affect the mechanical properties. Apart from this, it must be noted that the general process conditions are different in the cited studies. Nevertheless, the comparison between the mechanical properties is sufficiently accurate to show differences between the conventional sputtering methods.

In particular, other studies show that the high number of metal ions with high energies in HPPMS discharges support the formation of fcc-AlTiN (200) phases with higher hardness than the one of the dcMS typical fcc-AlTiN (111) phase [15]. Therefore, the occurrence of fcc-AlTiN (200) phase is typical for HPPMS coatings. Another reason for the high hardness of the AlTiN coatings sputtered by HPPMS is a highly dense, heterogenic, and granular crystal structure of the film with nanometre-sized hard fcc-AlTiN (200) and w-AlTiN phases as shown in Sections 3.4 and 3.5. Moreover, Alami et al. [15] report on the high hardness of HPPMS coatings resulting from the dense, granular structure with less porosities and the specific phase formation due to the high number of singleand double-charged $\mathrm{Al}$ - and $\mathrm{Ti}$-ions and the presence of atomic nitrogen, too. In this case, the AlTiN phase structures do not change at different pulse-frequencies in the range of $100 \mathrm{~Hz}$ to $500 \mathrm{~Hz}$ (see Figure 5). Thus, the deviations in hardness and elastic modulus for various pulse-frequencies result from differences in elemental composition and coating structure and not from different AlTiN phases. According to other authors [42] differences in film microstructure like porosity, internal stress, and structure defects are responsible for different mechanical properties, too. In particular, small grain sizes are technologically attractive due to the fact that they do not affect ductility and toughness negatively [42]. The effect of grain size refinement on the yield stress is generally described by the Hall-Petch relationship, based on dislocation pile-up at grain boundaries [42, 51]. However, this relationship does not work for nanometre-sized grains with limited dislocation plasticity as the high hardness of the AlTiN coating deposited at $300 \mathrm{~Hz}$ shows. Such a behaviour is discussed by several authors who reported softening of the material for grain sizes below a defined critical grain size $d_{c}$, where the stress required for dislocation motion or formation becomes larger than that for grain boundary sliding [42, 5255]. The hardness is also influenced by the fact that it becomes more difficult for dislocations to run through several grains as neighbouring grains have different lattice structures and slip systems [42]. Based on these facts, it is assumed that the critical grain size $d_{c}$ is reached at $300 \mathrm{~Hz}$ due to the highest hardness. This assumption is confirmed by the relatively uniform elemental composition of $\mathrm{Ti}, \mathrm{Al}$, and $\mathrm{N}$ content (see Section 3.3), suggesting a balanced grain growth, whereas the grain size at higher frequencies seems to be smaller than $d_{c}$ causing a reduction in hardness. The increasing porosity at higher frequencies leads to decreasing elastic modulus and hardness, too.

The calculated elastic strain to failure $(H / E$-factor) and resistance against plastic deformation $\left(H^{3} / E^{2}\right.$-factor) in Table 4 and Figures 12(b) and 12(c) describes the relation between hardness and elastic properties of AlTiN coatings deposited at different pulse-frequencies. This relationship is an important factor for describing the resistance behaviour of hard coatings, because wear resistance during external loading depends on the property to withstand mechanical penetration and to relieve stresses through elastic and plastic deformation. Here, both ratios of hardness and elastic modulus show a parabolic trend with maxima for the AlTiN coating deposited at $300 \mathrm{~Hz}$. This is attributed to the high hardness in combination with a low elastic modulus due to an optimized grain and phase-boundary structure. In the most cases of nanocomposite coatings $H^{3} / E^{2}$ shows a maximum for coatings with very high density of phase-boundaries [42]. Therefore, it is concluded that the AlTiN coating deposited at $300 \mathrm{~Hz}$ shows the best mechanical properties for cutting tools, which need high hardness and low elastic modulus in the scale of the substrate material to minimize the risk of spalling $[56,57]$.

This conclusion is confirmed by a ratio of $H / E^{*}=0.18 \geq$ 0.1 and a high elastic recovery of $W_{e}=59.3 \%$, which were described as key parameters for the resistance against cracking of hard coating by Musil [33]. As shown in Table 4, the mechanical properties of the AlTiN coatings deposited at lower and higher pulse-frequencies than $300 \mathrm{~Hz}$ result in a ratio $H / E^{*} \geq 0.1$, too. The elastic recovery varies with the pulse-frequencies. For this reason, no general trend for the resistance against cracking of AlTiN coatings at different pulse-frequencies can be concluded.

3.7. Surface Roughness and Topography. Analyses on surface morphology and topography of AlTiN coatings depending on HPPMS pulse-frequencies were performed by atomic force microscopy (AFM). This measurement method enables statistical analysis of the surface roughness and detailed studies of surface structures like hills or holes. The surface roughness values in Figure 13 generally show a decreasing trend for higher frequencies due to the decreasing presumption of droplets or droplet-like structures by avoiding arc events and the formation of a nitride layer. An exception is the AlTiN coating deposited at $500 \mathrm{~Hz}$, which is regarded as an outlier, due to the strong deviation of the calculated roughness $R_{\mathrm{ms}}$ as a result of the comparatively large droplet (Figure 16). Therefore, the number of elevated hill-like structures and holes decreases for higher frequencies as Figures 14-16 show. This correlates with the decreasing trend of the surface roughness with increasing frequency. In addition, the graphical images of the surface generated by measured data and the SEM images show that films deposited by HPPMS at various frequencies have heterogeneous topography and a typical surface for depositions under ion bombardment. In general, because of the coating structure, such coating surfaces are 


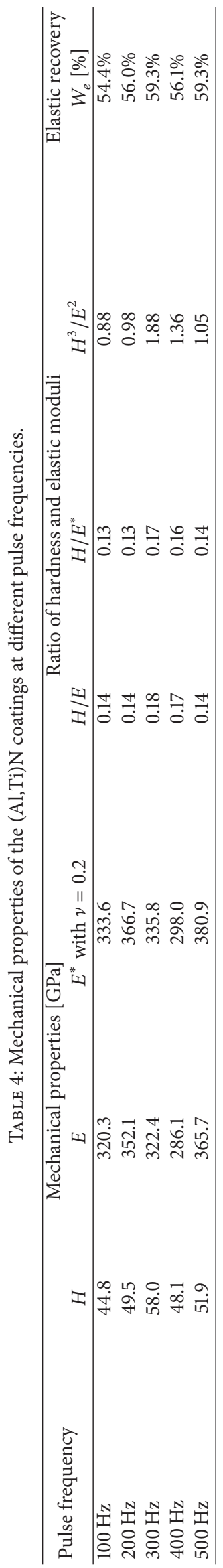




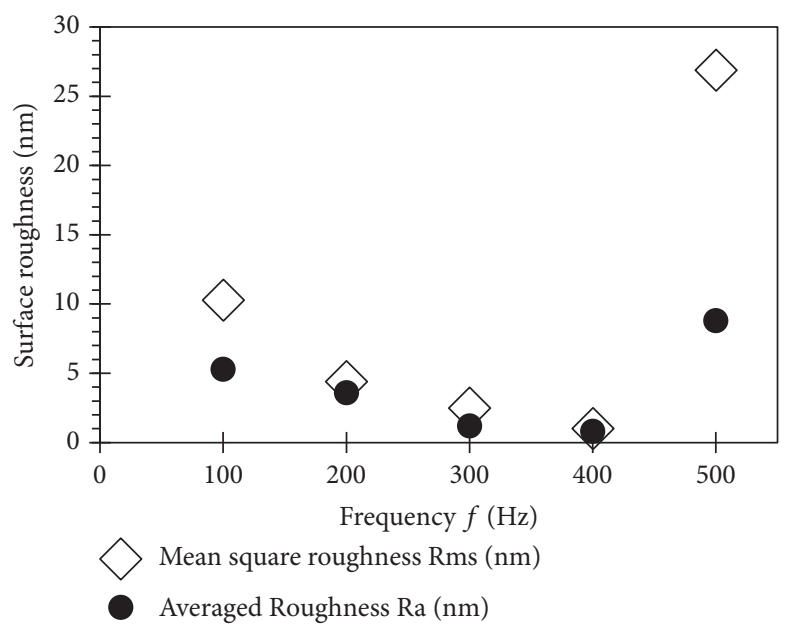

FIGURE 13: Surface roughness $R_{\mathrm{ms}}$ and $R_{a}$ of sputtered AlTiN coatings at various pulse-frequency in the range of $100-500 \mathrm{~Hz}$ determined via AFM measurements.

(a)

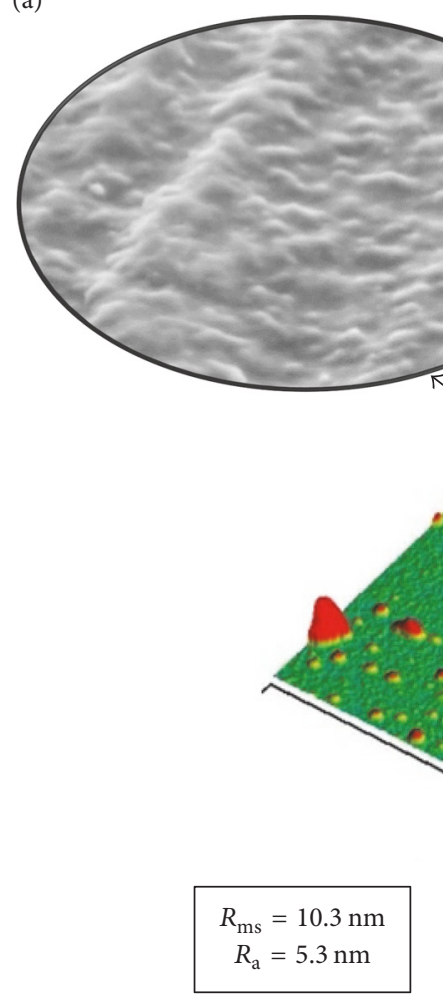

(b)
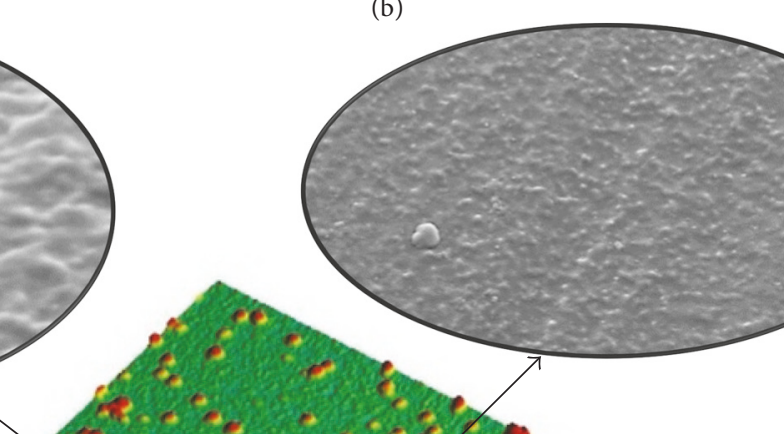


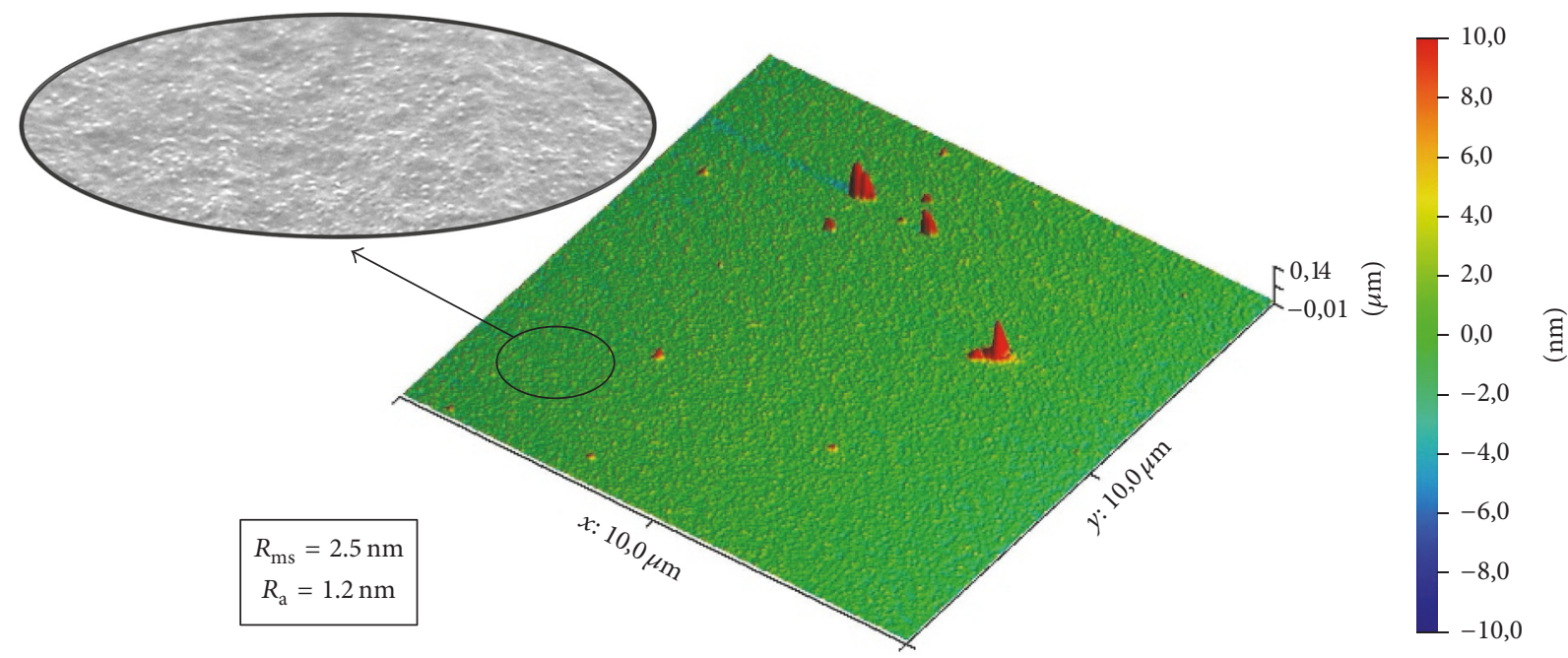

FIGURE 15: AFM image of the AlTiN coating surface deposited at $300 \mathrm{~Hz}$ for a scanned area of $10 \times 10 \mu \mathrm{m}$ with a maximal structure height of $140 \mathrm{~nm}$ and a maximal structure depth of $-13 \mathrm{~nm}$. The SEM image on the left side illustrates the surface structure in the nanometre range as an example for the marked surface area.

(a)

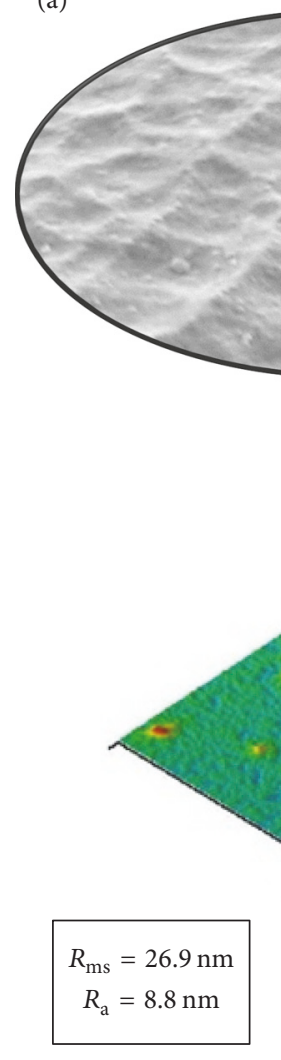

(b)

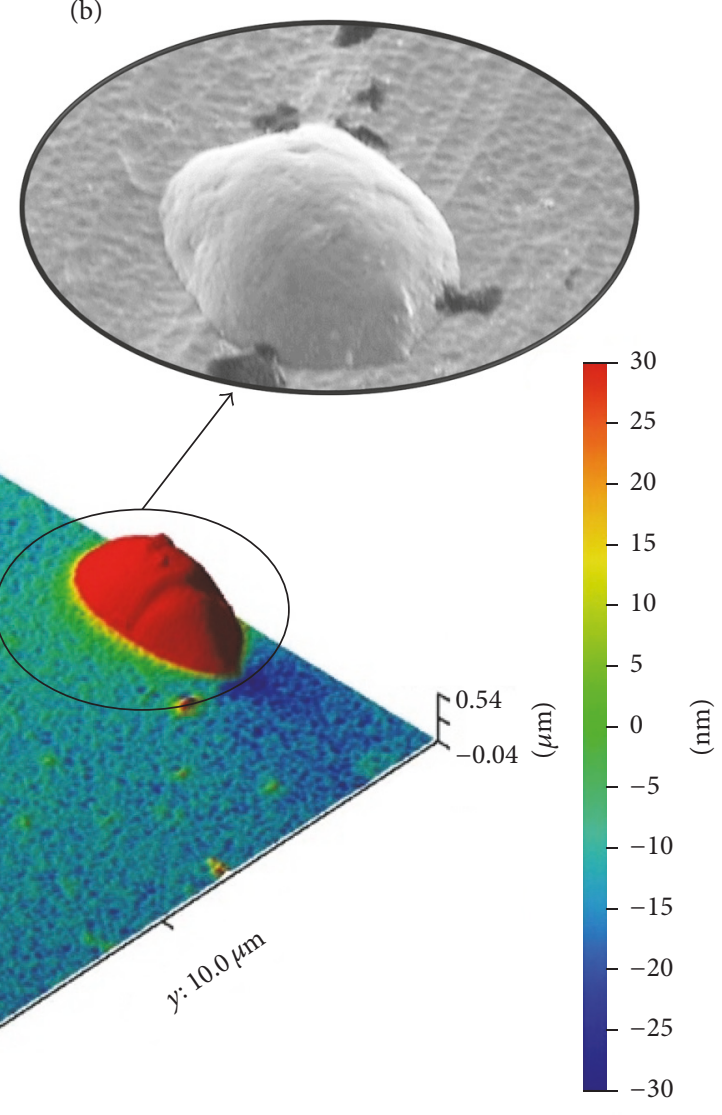

Figure 16: AFM image of the AlTiN coating surface deposited at $500 \mathrm{~Hz}$ for a scanned area of $10 \times 10 \mu \mathrm{m}$ with a maximal structure height of $542 \mathrm{~nm}$ (droplet) and a maximal structure depth of $-37 \mathrm{~nm}$. The SEM image on the left (a) illustrates the surface structure in the nanometre range as an example for the marked surface area. The SEM image on the right (b) shows a comparable sized and formed droplet like in the red coloured region in the AFM image. 
root mean square roughness $R_{\mathrm{ms}}$ is $10.3 \mathrm{~nm}$ and the average roughness $R_{a}$ is $5.3 \mathrm{~nm}$. In addition to the hill-like structures, the layer surface has deep, hole-like structures, which are presumably caused by the high energetic ion bombardment. The ions have enough energy to resputter and remove deposited coating material, leaving crater or ratholing on the surface. It is assumed that the resputtered film atoms can deposit in the vicinity of these holes and take part in formation of the abovementioned elevated structures (red marked). Further investigations are required to verify these assumptions and are not part of this work.

In comparison to $100 \mathrm{~Hz}$, the surface of the coating deposited at $300 \mathrm{~Hz}$ (Figure 15) shows the smoother surface with only few elevated structures with a maximum height of around $160 \mathrm{~nm}$. No holes can be seen in this case. For this reason, the pulse-frequency of $300 \mathrm{~Hz}$ leads to one of the lowest values of mean square roughness $R_{\mathrm{ms}}$ of $2.5 \mathrm{~nm}$ and average roughness $R_{a}$ of $1.2 \mathrm{~nm}$ in the current study. The smoothest surface with the lowest roughness of $R_{\mathrm{ms}}=$ $1.03 \mathrm{~nm}$ and $R_{a}=0.81 \mathrm{~nm}$ was deposited at a pulsefrequency of $400 \mathrm{~Hz}$, as shown in Figure 13.

The highest surface roughness with $R_{\mathrm{ms}}$ of $26.9 \mathrm{~nm}$ and $R_{a}$ of $8.8 \mathrm{~nm}$ was calculated for the coating deposited at $500 \mathrm{~Hz}$, due to the large droplet height of about $540 \mathrm{~nm}$ and a lateral size of about $3 \mu \mathrm{m}$ as shown in Figure 16. Apart from this, the coating shows less hill-like structures and a smoother surface compared to the one deposited at $100 \mathrm{~Hz}$. In contrast to the nearly spherical hill-like structures of the one deposited at $100 \mathrm{~Hz}$ this one shows an irregular growth-related hillstructure, mostly located close to holes. For this reason, it is assumed that the irregular elevated structure growth results from differences in the local surface potential, caused by surface defects, leading to irregular material deposition on the surface.

In summary, the study shows that the surface roughness of AlTiN coatings sputtered by HPPMS is strongly affected by the pulse-frequencies and the resulting discharge parameters, especially current density and power density. According to this, the surface roughness depends on the general coating growth conditions, determined by the pulseon/off-configuration. Therefore, the smoothest surface was formed at a pulse-frequency of 300 and $400 \mathrm{~Hz}$, which belongs to a duty cycle of $1.5 \%$ and $2.0 \%$. Thus, for AlTiN coatings deposited by HPPMS with pulse lengths of $50 \mu \mathrm{s}$ and under similar deposition conditions like in this study, a frequency of 300 and $400 \mathrm{~Hz}$ leads to very low roughness and very good surface properties, which is beneficial for cutting tools.

\section{Conclusion}

In this study, the influence of the HPPMS frequency on plasma discharges and AlTiN coating properties was investigated with focus on the relation between the plasma and deposition conditions. The results show a strong dependence of the frequencies on deposition rate, elemental composition, surface roughness, and mechanical properties, which influence each other as well. The AlTiN two-phase structure analysed by XRD are not influenced by the pulsefrequency. Therefore, it is assumed that pulse length and resulting temporal plasma properties during pulse-on-time, like ion-to-neutral ratio and metal ion energy, are the most influencing parameters. The specific results in this study for AlTiN coatings deposited by HPPMS can be used as points of reference to indicate the potential of mechanical properties. In this case, the best properties for cutting tools like high hardness, low elastic modulus, and a smooth surface were reached for the AlTiN coating deposited at 300 and $400 \mathrm{~Hz}$ for a pulse length of $50 \mu \mathrm{s}$. For other pulse lengths, the optimum frequency can be different depending on the pulseon/off-configuration. For this reason, further investigations with different HPPMS process parameters are necessary to expand the range of optimum processing parameters for industrial applications.

The results also demonstrate the advantages of AlTiN coatings deposited by HPPMS comparing to coating deposition by dcMS:

(1) AlTiN coatings by HPPMS show smoother surfaces as AlTiN coatings by dcMS. In addition, the surface roughness can be varied with pulse-frequency, whereby higher frequencies lead to smoother surfaces without changing the AlTiN phase structure.

(2) The pulsed mode minimizes the formation of nitride layers, leading to surface charges and resulting in unwanted arc events.

(3) HPPMS improves the coverage and uniform coating thickness of complex-shaped substrates because the increased number of ions together with the bias potential allows controlling the layer-forming particles. The increased ion-to-neutral ratio also leads to an (200)-orientation of the fcc-AlTiN phase. Those oriented fcc-AlTiN phases show a higher hardness as the (111)-orientation, which is typical of discharges dominated by neutral sputtered particles.

(4) Without a separate heating for a constant process temperature of $500^{\circ} \mathrm{C}$ as in this study, AlTiN coatings deposited by HPPMS can be used as wear-resistant coating for flexible and/or thermosensitive substrates like polymer due to the low normalized thermal energy flux comparing to dcMS or cathodic-arc evaporation.

\section{Conflicts of Interest}

The authors declare that there are no conflicts of interest regarding the publication of this paper.

\section{Acknowledgments}

The authors would like to thank Dr. Markus Ratzke for his technical assistance in AFM measurements and Dr. Aleksei Obrosov for his assistance in laboratory experiments. Special thanks are due to Dr. Heinz-Peter Stoll and Mr. David Stolarek from the Leibniz Institute for Innovations for High 
Performance Microelectronics (IHP GmbH, Frankfurt/Oder in Germany) for their support to obtain high quality SEM micrographs.

\section{References}

[1] J. Kruszynski, "Hochproduktive Werkzeugbeschichtungen," in Intelligent produzieren: Liber amicorum, S. Braun, Ed., pp. 184196, Springer-Verlag Berlin Heidelberg, Berlin Heidelberg, 2010.

[2] O. Knotek, "Industrial deposition of binary, ternary, and quaternary nitrides of titanium, zirconium, and aluminum," Journal of Vacuum Science \& Technology A, vol. 5, no. 4, pp. 2173-2179, 1987.

[3] M. Naveed, A. Obrosov, and S. Weiß, "Investigation of the Wear Resistance Properties of Cr/CrN Multilayer Coatings against Sand Erosion," Conference Papers in Science, vol. 2015, pp. 1-9, 2015.

[4] A. Obrosov, A. Sutygina, A. Volinsky, A. Manakhov, S. Weiß, and E. Kashkarov, "Effect of Hydrogen Exposure on Mechanical and Tribological Behavior of CrxN Coatings Deposited at Different Pressures on IN718," Materials, vol. 10, no. 6, p. 563, 2017.

[5] S. Braun, (Hrsg.): Intelligent produzieren: Liber amicorum, Springer-Verlag, Berlin Heidelberg, 2010.

[6] J. Musil and H. Hrubý, "Superhard nanocomposite Til-xAlxN films prepared by magnetron sputtering," Thin Solid Films, vol. 365, no. 1, pp. 104-109, 2000.

[7] K.-D. Bouzakis, N. Michailidis, G. Skordaris, E. Bouzakis, D. Biermann, and R. M'Saoubi, "Cutting with coated tools: coating technologies, characterization methods and performance optimization," CIRP Annals - Manufacturing Technology, vol. 61, no. 2, pp. 703-723, 2012.

[8] J. D. Bressan, R. Hesse, and E. M. Silva, "Abrasive wear behavior of high speed steel and hard metal coated with TiAlN and TiCN," Wear, vol. 250-251, pp. 561-568, 2001.

[9] D. McIntyre, J. E. Greene, G. Håkansson, J.-E. Sundgren, and W.-D. Münz, "Oxidation of metastable single-phase polycrystalline Ti 0.5Al0.5N films: Kinetics and mechanisms," Journal of Applied Physics, vol. 67, no. 3, pp. 1542-1553, 1990.

[10] A. Obrosov, R. Gulyaev, M. Ratzke et al., "XPS and AFM investigations of Ti-Al-N coatings fabricated using DC magnetron sputtering at various nitrogen flow rates and deposition temperatures," Metals, vol. 7, no. 2, article no. 52, 2017.

[11] M. Schulze, H. Seidlitz, F. Konig, and S. WeiB, "Tribological Investigations of PVD Coated Multi-Layer Constructions," Journal of Materials Science Research, vol. 5, no. 1, p. 97, 2015.

[12] J. W. Bradley, S. Thompson, and Y. Aranda Gonzalvo, "Measurement of the plasma potential in a magnetron discharge and the prediction of the electron drift speeds," Plasma Sources Science and Technology, vol. 10, no. 3, pp. 490-501, 2001.

[13] K. Sarakinos, J. Alami, and S. Konstantinidis, "High power pulsed magnetron sputtering: a review on scientific and engineering state of the art," Surface and Coatings Technology, vol. 204, no. 11, pp. 1661-1684, 2010.

[14] J. T. Gudmundsson, J. Alami, and U. Helmersson, "Spatial and temporal behavior of the plasma parameters in a pulsed magnetron discharge," Surface and Coatings Technology, vol. 161, no. 2-3, pp. 249-256, 2002.

[15] J. Alami, S. Bolz, and K. Sarakinos, "High power pulsed magnetron sputtering: fundamentals and applications," Journal of Alloys and Compounds, vol. 483, no. 1-2, pp. 530-534, 2009.
[16] A. Obrosov, M. Naveed, A. A. Volinsky, and S. Weiß, "Substrate Frequency Effects on Cr xN Coatings Deposited by DC Magnetron Sputtering," Journal of Materials Engineering and Performance, vol. 26, no. 1, pp. 366-373, 2017.

[17] J. T. Gudmundsson, N. Brenning, D. Lundin, and U. Helmersson, "High power impulse magnetron sputtering discharge," Journal of Vacuum Science \& Technology A, vol. 30, 2012.

[18] K. Bobzin, T. Brögelmann, and R. H. Brugnara, "Aluminumrich HPPMS (Cr1-xAlx)N coatings deposited with different target compositions and at various pulse lengths," Vacuum, vol. 122, pp. 201-207, 2015.

[19] G. Greczynski and L. Hultman, "Time and energy resolved ion mass spectroscopy studies of the ion flux during high power pulsed magnetron sputtering of $\mathrm{Cr}$ in $\mathrm{Ar}$ and $\mathrm{Ar} / \mathrm{N} 2$ atmospheres," Vacuum, vol. 84, no. 9, pp. 1159-1170, 2010.

[20] D. Lundin, S. A. Sahab, N. Brenning, C. Huo, and U. Helmersson, "Internal current measurements in high power impulse magnetron sputtering," Plasma Sources Science and Technology, vol. 20, no. 4, p. 045003, 2011.

[21] C. Vitelaru, D. Lundin, G. D. Stancu, N. Brenning, J. Bretagne, and T. Minea, "Argon metastables in HiPIMS: Time-resolved tunable diode-laser diagnostics," Plasma Sources Science and Technology, vol. 21, no. 2, Article ID 025010, 2012.

[22] M. A. Raadu, I. Axnäs, J. T. Gudmundsson, C. Huo, and N. Brenning, "An ionization region model for high-power impulse magnetron sputtering discharges," Plasma Sources Science and Technology, vol. 20, no. 6, Article ID 065007, 2011.

[23] S. Kadlec, "Simulation of neutral particle flow during high power magnetron impulse," Plasma Processes and Polymers, vol. 4, no. 1, pp. S419-S423, 2007.

[24] J. Bohlmark, M. Lattemann, J. T. Gudmundsson et al., “The ion energy distributions and ion flux composition from a high power impulse magnetron sputtering discharge," Thin Solid Films, vol. 515, no. 4, pp. 1522-1526, 2006.

[25] K. Bobzin, T. Brögelmann, R. H. Brugnara, N. C. Kruppe, and S. Chromy, "Influence of HPPMS pulse parameters on the reactive gas N2 and on the properties of (Cr, Al)N coatings," Surface and Coatings Technology, vol. 293, pp. 28-34, 2016.

[26] C. Maszl, W. Breilmann, J. Benedikt, and A. Von Keudell, "Origin of the energetic ions at the substrate generated during high power pulsed magnetron sputtering of titanium," Journal of Physics D: Applied Physics, vol. 47, no. 22, Article ID 224002, 2014.

[27] W. Breilmann, C. Maszl, J. Benedikt, and A. Von Keudell, "Dynamic of the growth flux at the substrate during high-power pulsed magnetron sputtering (HiPIMS) of titanium," Journal of Physics D: Applied Physics, vol. 46, no. 48, Article ID 485204, 2013.

[28] P. M. Martin, Handbook of deposition technologies for films and coatings: Science, applications and technology, Oxford: William Andrew; Elsevier Science, NY, USA, 3rd edition, 2009.

[29] M. Samuelsson, D. Lundin, J. Jensen, M. A. Raadu, J. T. Gudmundsson, and U. Helmersson, "On the film density using high power impulse magnetron sputtering," Surface and Coatings Technology, vol. 205, no. 2, pp. 591-596, 2010.

[30] U. Helmersson, M. Lattemann, J. Bohlmark, A. P. Ehiasarian, and J. T. Gudmundsson, "Ionized physical vapor deposition (IPVD): a review of technology and applications," Thin Solid Films, vol. 513, no. 1-2, pp. 1-24, 2006.

[31] D. J. Christie, "Target material pathways model for high power pulsed magnetron sputtering," Journal of Vacuum Science \& Technology A, vol. 23, no. 2, pp. 330-335, 2005. 
[32] J. Emmerlich, S. Mráz, R. Snyders, K. Jiang, and J. M. Schneider, "The physical reason for the apparently low deposition rate during high-power pulsed magnetron sputtering," Vacuum, vol. 82, no. 8, pp. 867-870, 2008.

[33] J. Musil, "Flexible hard nanocomposite coatings," RSC Advances, vol. 5, no. 74, pp. 60482-60495, 2015.

[34] D. Rafaja, C. Wüstefeld, M. Dopita et al., "Crystallography of phase transitions in metastable titanium aluminium nitride nanocomposites," Surface and Coatings Technology, vol. 257, pp. 26-37, 2014.

[35] G. Greczynski, J. Lu, J. Jensen et al., "A review of metal-ion-fluxcontrolled growth of metastable TiAlN by HIPIMS/DCMS cosputtering," Surface and Coatings Technology, vol. 257, pp. 15-25, 2014.

[36] G. Greczynski, J. Lu, M. P. Johansson et al., "Role of Ti n+ and Al $\mathrm{n}+$ ion irradiation $(\mathrm{n}=1,2)$ during Ti $1-\mathrm{xAl} \mathrm{xN}$ alloy film growth in a hybrid HIPIMS/magnetron mode," Surface and Coatings Technology, vol. 206, no. 19-20, pp. 4202-4211, 2012.

[37] G. West, P. Kelly, P. Barker, A. Mishra, and J. Bradley, "Measurements of deposition rate and substrate heating in a HiPIMS discharge," Plasma Processes and Polymers, vol. 6, no. 1, pp. S543-S547, 2009.

[38] J. E. Greene, J.-E. Sundgren, L. Hultman, I. Petrov, and D. B. Bergstrom, "Development of preferred orientation in polycrystalline TiN layers grown by ultrahigh vacuum reactive magnetron sputtering," Applied Physics Letters, vol. 67, p. 2928, 1995.

[39] M. Marlo and V. Milman, "Density-functional study of bulk and surface properties of titanium nitride using different exchangecorrelation functionals," Physical Review B: Condensed Matter and Materials Physics, vol. 62, no. 4, pp. 2899-2907, 2000.

[40] P. Patsalas, C. Gravalidis, and S. Logothetidis, "Surface kinetics and subplantation phenomena affecting the texture, morphology, stress, and growth evolution of titanium nitride films," Journal of Applied Physics, vol. 96, no. 11, pp. 6234-6235, 2004.

[41] A. P. Ehiasarian, A. Vetushka, Y. A. Gonzalvo, G. Sfrn, L. Székely, and P. B. Barna, "Influence of high power impulse magnetron sputtering plasma ionization on the microstructure of TiN thin films," Journal of Applied Physics, vol. 109, no. 10, Article ID 104314, 2011.

[42] P. H. Mayrhofer, C. Mitterer, and J. Musil, "Structure-property relationships in single- and dual-phase nanocrystalline hard coatings," Surface and Coatings Technology, vol. 174-175, pp. 725-731, 2003.

[43] C. Suryanarayana, "Nanocrystalline materials," International Materials Reviews, vol. 40, no. 2, pp. 41-63, 1995.

[44] R. Messier, A. P. Giri, and R. A. Roy, "Revised Structure Zone Model for Thin Film Physical Structure," Journal of Vacuum Science \& Technology A, vol. 2, no. 2, pp. 500-503, 1984.

[45] J.-E. Sundgren, "Structure and properties of TiN coatings," Thin Solid Films, vol. 128, no. 1-2, pp. 21-44, 1985.

[46] D. M. Mattox, "Particle bombardment effects on thin-film deposition: A review," Journal of Vacuum Science \& Technology A, vol. 7, no. 3, pp. 1105-1114, 1989.

[47] J. A. Thornton, "High rate thick film growth," Annual Review of Materials Research, vol. 7, pp. 239-260, 1977.

[48] M. Keunecke, C. Stein, K. Bewilogua, W. Koelker, D. Kassel, and H. V. den Berg, "Modified TiAlN coatings prepared by d.c. pulsed magnetron sputtering," Surface and Coatings Technology, vol. 205, no. 5, pp. 1273-1278, 2010.
[49] M. Jílek Jr., M. Jílek, F. Mendez Martin, P. H. Mayrhofer, and S. Veprek, "High-rate deposition of AlTiN and related coatings with dense morphology by central cylindrical direct current magnetron sputtering," Thin Solid Films, vol. 556, pp. 361-368, 2014.

[50] J. Nohava, P. Dessarzin, P. Karvankova, and M. Morstein, "Characterization of tribological behavior and wear mechanisms of novel oxynitride PVD coatings designed for applications at high temperatures," Tribology International, vol. 81, article no. 3425, 2015.

[51] E. O. Hall, "The deformation and ageing of mild steel: III discussion of results," Proceedings of the Physical Society, Section $B$, vol. 64, no. 9, pp. 747-752, 1951.

[52] P. H. Mayrhofer, G. Tischler, and C. Mitterer, "Microstructure and mechanical/thermal properties of $\mathrm{Cr}-\mathrm{N}$ coatings deposited by reactive unbalanced magnetron sputtering," Surface and Coatings Technology, vol. 142-144, pp. 78-84, 2001.

[53] E. Arzt, "Size effects in materials due to microstructural and dimensional constraints: a comparative review," Acta Materialia, vol. 46, no. 16, pp. 5611-5626, 1998.

[54] H. S. Kim and Y. Estrin, "Phase mixture modeling of the strain rate dependent mechanical behavior of nanostructured materials," Acta Materialia, vol. 53, no. 3, pp. 765-772, 2005.

[55] H. S. Kim, Y. Estrin, and M. B. Bush, "Plastic deformation behaviour of fine-grained materials," Acta Materialia, vol. 48, no. 2, pp. 493-504, 2000.

[56] A. Leyland and A. Matthews, "On the significance of the $H / E$ ratio in wear control: a nanocomposite coating approach to optimised tribological behaviour," Wear, vol. 246, no. 1-2, pp. $1-11,2000$.

[57] J. Musil, F. Kunc, H. Zeman, and H. Poláková, "Relationships between hardness, Young's modulus and elastic recovery in hard nanocomposite coatings," Surface and Coatings Technology, vol. 154, no. 2-3, pp. 304-313, 2002. 

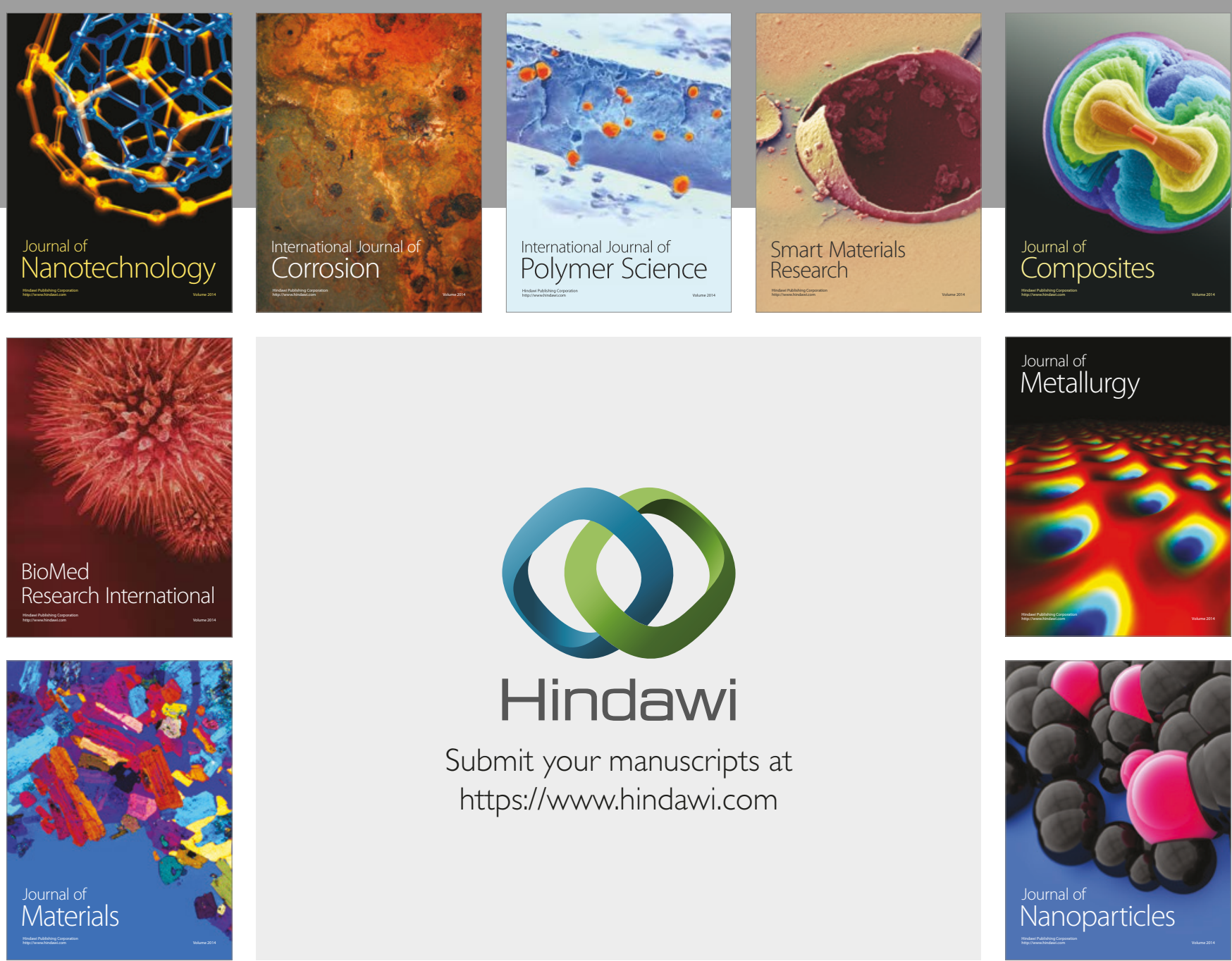

\section{Hindawi}

Submit your manuscripts at

https://www.hindawi.com
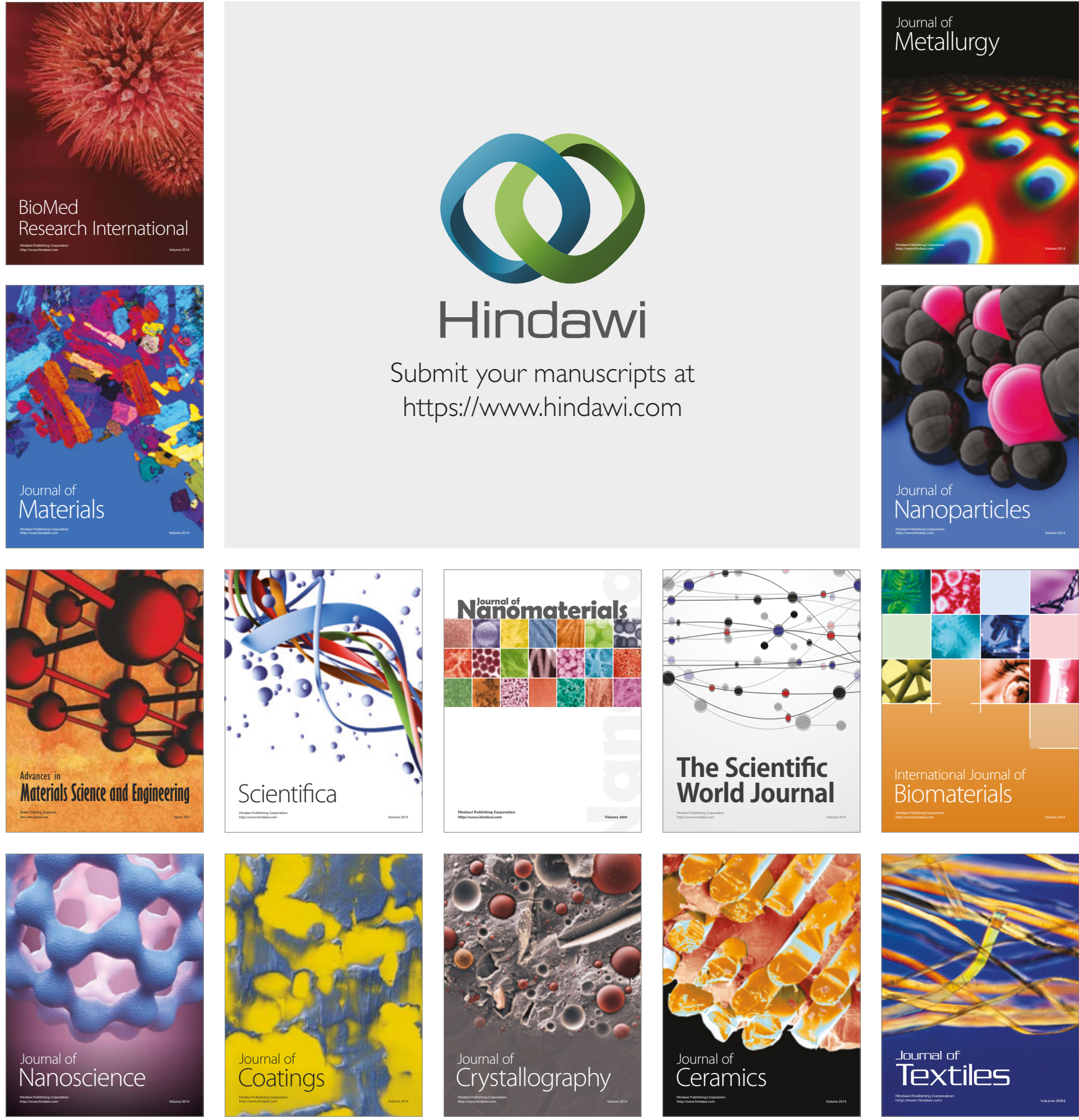

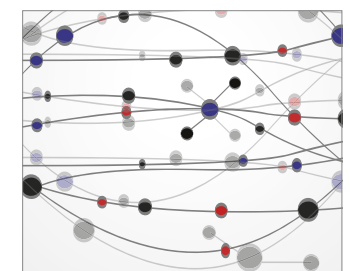

The Scientific World Journal
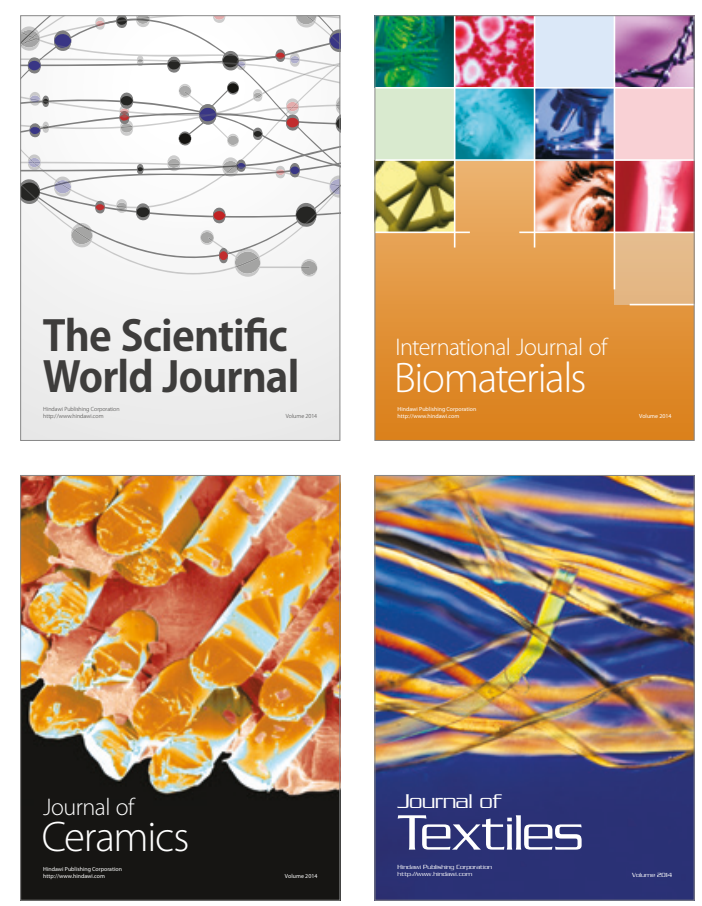